\title{
Predicting photosynthesis and transpiration responses to ozone: decoupling modeled photosynthesis and stomatal conductance
}

\author{
D. Lombardozzi ${ }^{1}$, S. Levis ${ }^{2}$, G. Bonan ${ }^{2}$, and J. P. Sparks ${ }^{1}$ \\ ${ }^{1}$ Department of Ecology and Evolutionary Biology, Corson Hall, Cornell University, Ithaca, NY 14853, USA \\ ${ }^{2}$ National Center for Atmospheric Research, P.O. Box 3000, Boulder, CO 80307-3000, USA
}

Correspondence to: D. Lombardozzi (d1129@cornell.edu)

Received: 28 February 2012 - Published in Biogeosciences Discuss.: 10 April 2012

Revised: 12 July 2012 - Accepted: 15 July 2012 - Published: 13 August 2012

\begin{abstract}
Plants exchange greenhouse gases carbon dioxide and water with the atmosphere through the processes of photosynthesis and transpiration, making them essential in climate regulation. Carbon dioxide and water exchange are typically coupled through the control of stomatal conductance, and the parameterization in many models often predict conductance based on photosynthesis values. Some environmental conditions, like exposure to high ozone $\left(\mathrm{O}_{3}\right)$ concentrations, alter photosynthesis independent of stomatal conductance, so models that couple these processes cannot accurately predict both. The goals of this study were to test direct and indirect photosynthesis and stomatal conductance modifications based on $\mathrm{O}_{3}$ damage to tulip poplar (Liriodendron tulipifera) in a coupled Farquhar/Ball-Berry model. The same modifications were then tested in the Community Land Model (CLM) to determine the impacts on gross primary productivity (GPP) and transpiration at a constant $\mathrm{O}_{3}$ concentration of 100 parts per billion (ppb). Modifying the $V_{\text {cmax }}$ parameter and directly modifying stomatal conductance best predicts photosynthesis and stomatal conductance responses to chronic $\mathrm{O}_{3}$ over a range of environmental conditions. On a global scale, directly modifying conductance reduces the effect of $\mathrm{O}_{3}$ on both transpiration and GPP compared to indirectly modifying conductance, particularly in the tropics. The results of this study suggest that independently modifying stomatal conductance can improve the ability of models to predict hydrologic cycling, and therefore improve future climate predictions.
\end{abstract}

\section{Introduction}

Surface vegetation has a strong, direct effect on climate through regulating both carbon and hydrologic cycles on regional and global scales (Bonan, 2008). Often, carbon and water exchange between plants and the atmosphere is closely coupled. On a leaf level, stomatal aperture controls the amount of carbon entering and water exiting the leaf, and responds to changes in many environmental parameters, such as light, temperature, and carbon dioxide concentrations (Jones, 1998; Schroeder et al., 2001). Though regulation of stomatal conductance is the primary mechanism plants use to regulate water loss via transpiration, it is only one of the mechanisms controlling photosynthetic carbon gain; biochemical assimilation of carbon (carboxylation) also plays a large role (Cowan and Troughto, 1971; Jones, 1998; von Caemmerer and Farquhar, 1981). Under circumstances where carboxylation is damaged or not limited by stomatal conductance, photosynthesis and conductance can become decoupled. For example, many $\mathrm{C}_{3}$ plants do not completely close stomatal guard cells at night resulting in water loss during a time when carboxylation does not occur due to a lack of light (Caird et al., 2007). Also, when plants are exposed to high light levels or high ozone $\left(\mathrm{O}_{3}\right)$ concentrations, membranes and photosystems become oxidized, decreasing carboxylation rates often without decreasing stomatal conductance at the same rate or magnitude (Calatayud et al., 2007; Demmig-Adams and Adams, 2006; Francini et al., 2007; Maier-Maercker and Koch, 1991; Matyssek et al., 1991; Paoletti and Grulke, 2005; Pearson and Mansfield, 1993; Tjoelker et al., 1995). In all of these scenarios, photosynthesis and stomatal conductance can become decoupled, 
changing the relationship between carbon gain and water loss.

Models are a primary method of studying how vegetation interacts with climate on regional and global scales. Often, models scale leaf-level physiology to ecosystem and global levels by assuming that photosynthesis and transpiration are closely coupled and, in fact, calculate stomatal conductance based on photosynthetic values. For example, the physiological model of photosynthesis derived by Farquhar (Farquhar et al., 1980) and the Ball-Berry model of stomatal conductance (Ball, 1987) are commonly used together in regional and global models and accurately predict observed photosynthesis and stomatal conductance under many conditions (Collatz et al., 1991; Harley et al., 1992; Misson et al., 2004; von Caemmerer and Farquhar, 1981). In this formulation, the photosynthesis calculations are influenced by feedbacks from changes in stomatal conductance because conductance regulates internal carbon dioxide $\left(\mathrm{CO}_{2}\right)$ concentration $\left(c_{i}\right)$, which drives the biochemical components of photosynthesis (see Eq. 1 in Sect. 2.1.1). The Ball-Berry conductance equation is calculated directly from photosynthetic rates (see Eq. 2 in Sect. 2.1.1), in addition to other factors like ambient $\mathrm{CO}_{2}$ concentration $\left(\left[\mathrm{CO}_{2}\right]\right)$, a relative humidity gradient, and atmospheric partial pressure.

Despite the accuracy of the Farquhar/Ball-Berry physiological model in many situations, conditions that increase or decrease carboxylation without subsequent changes in stomatal conductance cannot be accurately predicted due to the direct dependence of stomatal conductance calculations on the photosynthetic rate. For example, the relationship between photosynthesis and transpiration changes after chronic $\mathrm{O}_{3}$ exposure due to damage to functional aspects of both carboxylation and stomatal conductance, causing larger decreases in photosynthesis than transpiration (Calatayud et al., 2007; Francini et al., 2007; Maier-Maercker and Koch, 1991; Matyssek et al., 1991; Paoletti, 2005; Pearson and Mansfield, 1993; Tjoelker et al., 1995). Evidence suggests that models using Farquhar/Ball-Berry equations to predict $\mathrm{O}_{3}$ damage to photosynthesis with proportional responses in conductance (Felzer et al., 2004; Ollinger et al., 1997; Sitch et al., 2007) likely predict overly large decreases in stomatal conductance (Lombardozzi et al., 2012) that, when scaled from leaf-level responses to regional and global responses through time, may result in large inaccuracies in predicted transpiration. Sitch et al. (2007) predicted that $\mathrm{O}_{3}$ has a large, indirect impact on climate through suppressing photosynthesis resulting in more $\mathrm{CO}_{2}$ in the atmosphere. However, the method used in the simulation assumed a proportional decrease in stomatal conductance. Incorporating independent responses of photosynthesis and stomatal conductance to $\mathrm{O}_{3}$ in models will likely cause transpiration to decrease less than predicted by previous simulations, causing soil moisture to increase less than predicted while atmospheric water vapor will not decrease to the extent predicted. The combination of these two effects will cause changes in ecosystem hydrology and climate in addition to those predicted by the increase in $\mathrm{CO}_{2}$ concentrations alone.

Ozone damage to plants is a unique yet important scenario to incorporate into models because many regions already experience damaging concentrations ( $>40 \mathrm{ppb}$ ) that change the ability of plants to exchange carbon and water with the atmosphere (Wittig et al., 2007), an important ecosystem service in regulating climate (Bonan, 2008). Damage to photosynthesis, quantified in several meta-analyses and reviews (Feng et al., 2008; Morgan et al., 2003; Wittig et al., 2007), is caused by mechanisms that include reductions in leaf chlorophyll content that impact electron transport (Heagle et al., 1996; Sharma et al., 2003), declines in carboxylation efficiency through reductions in the quantity and activity of the primary carboxylation enzyme Rubisco (Fiscus et al., 2005), and/or direct damage to stomatal cells (Hassan et al., 1994; Manes et al., 2001; Torsethaugen et al., 1999). Though stomatal cells can impose a diffusional limitation to photosynthesis, several studies suggest that carboxylation and mesophyllic limitations are more important than stomatal limitation in trees exposed to $\mathrm{O}_{3}$ (Francini et al., 2007; Matyssek et al., 1991; Noormets et al., 2001; Reichenauer et al., 1997). Typically, stomata close in response to $\mathrm{O}_{3}$ as an indirect response to increasing internal $\mathrm{CO}_{2}$ concentration $\left(c_{i}\right)$ that results from decreases in carbon fixation (Paoletti, 2005). However, the magnitude of stomatal decrease is seldom equal to the magnitude of total photosynthetic decrease under chronic $\mathrm{O}_{3}$ exposure (Calatayud et al., 2007; Francini et al., 2007; Maier-Maercker and Koch, 1991; Matyssek et al., 1991; Novak et al., 2005; Paoletti, 2005; Pearson and Mansfield, 1993; Tjoelker et al., 1995).

Acute instantaneous exposure at moderate or high concentrations of $\mathrm{O}_{3}\left(\left[\mathrm{O}_{3}\right]\right)$ can cause instantaneous reductions in conductance similar in magnitude to photosynthesis (Farage et al., 1991). In contrast, chronic exposure often leads to sluggish stomatal responses to environmental stimuli due to loss of stomatal functioning and a decoupling of conductance from photosynthesis due to direct damage to biochemical carboxylation (Paoletti, 2005; Tjoelker et al., 1995). In fact, several studies demonstrate that sluggish stomatal cells can also result in increases in conductance and/or integrated diurnal transpiration (Gregg et al., 2006; Hassan et al., 1994; McLaughlin et al., 2007). These observations suggest that models can better represent the influence of chronic $\mathrm{O}_{3}$ through modifying parameters that estimate responses of carboxylation rather than total photosynthesis and by directly modifying stomatal conductance because it often responds independent of photosynthesis.

To date, regional and global models that have incorporated $\mathrm{O}_{3}$ damage to plants change only photosynthesis and assume a tight correlation between photosynthetic rate and stomatal conductance (Felzer et al., 2004, 2005; Ollinger et al., 1997; Ollinger et al., 2002; Ren et al., 2011; Sitch et al., 2007), allowing photosynthesis to ultimately drive changes in transpiration. Since experimental data suggest $\mathrm{O}_{3}$ damage to plants 
changes the relationship between photosynthesis and conductance, the standard Farquhar/Ball-Berry parameterization that couples these processes will not be capable of accurately predicting both processes. As a result, there are currently no accurate estimates of changes in some of the most important climate controls - transpiration, latent heat flux, hydrology and water cycling - due to $\mathrm{O}_{3}$ damage to plants.

The objectives of this work were to: (1) determine the best photosynthesis and stomatal conductance parameterization to predict physiological responses of tulip poplar to $\mathrm{O}_{3}$ in a leaf-level Farquhar photosynthesis/Ball-Berry conductance model; and (2) to incorporate the most accurate $\mathrm{O}_{3}$ parameterization into the Community Land Model version 4 (CLM4SP; described in Lawrence et al., 2011), the land component of the Community Earth System Model (CESM). To determine the best predictors of $\mathrm{O}_{3}$ damage, we expanded upon work by Lombardozzi et al. (2012) to test an additional method of modifying photosynthesis and stomatal conductance in a Farquhar photosynthesis/Ball-Berry conductance model. Using CLM4SP at a constant $\left[\mathrm{O}_{3}\right]$ of $100 \mathrm{ppb}$, we then determined the differences in global gross primary productivity (GPP) and transpiration due to direct changes to photosynthesis and stomatal conductance compared to indirect changes that alter transpiration by modifying photosynthesis. Using a high $\left[\mathrm{O}_{3}\right]$ and a single plant type allows us to more clearly determine whether $\mathrm{O}_{3}$ damage could be independently incorporated for photosynthesis and stomatal conductance by enlarging the differences from control simulations which do not incorporate $\mathrm{O}_{3}$. This study uniquely tests different methods of modifying photosynthesis and stomatal conductance and includes them into the framework of a global land model that allows us to indentify hotspots where $\mathrm{O}_{3}$ damage might have a large impact on GPP and transpiration.

\section{Methods}

\subsection{Farquhar photosynthesis/Ball-Berry conductance model description}

The Farquhar/Ball-Berry model predicts leaf-level photosynthesis and stomatal conductance over a range of environmental conditions. The specific implementation used here is the model used by Lombardozzi et al. (2012) and is a variant of the Ball-Berry stomatal conductance model (Ball et al., 1987; Collatz et al., 1991), the Farquhar et al. (1980) C 3 photosynthesis model extended to include product-limited photosynthesis (Harley and Sharkey, 1991; Harley et al., 1992) and $\mathrm{C}_{4}$ photosynthesis (Collatz et al., 1992). In this parameterization, the model represents photosynthetic uptake of $\mathrm{CO}_{2}$ as limited by: (i) Rubisco-limited photosynthesis, $A_{c}$, (ii) RuBP-limited photosynthesis, $A_{j}$, or (iii) product-limited photosynthesis, $A_{\mathrm{p}}$ (see equations in Bonan et al., 2011). The net $\mathrm{CO}_{2}$ assimilation rate, $A_{n}$, is
$A_{n}=\min \left(A_{c}, A_{j}, A_{\mathrm{p}}\right)-R_{\mathrm{d}}$

where $R_{\mathrm{d}}$ is dark respiration. The required internal leaf $\mathrm{CO}_{2}$ concentration $\left(c_{i}\right)$ is calculated from the diffusion equations:

$A_{n}=\left(c_{\mathrm{a}}-c_{\mathrm{s}}\right)\left(g_{\mathrm{b}} / 1.4\right)=\left(c_{\mathrm{s}}-c_{i}\right)\left(g_{\mathrm{s}} / 1.6\right)$

where $c_{\mathrm{a}}$ is the ambient $\left[\mathrm{CO}_{2}\right], c_{\mathrm{s}}$ is the $\left[\mathrm{CO}_{2}\right]$ at the leaf surface, $g_{\mathrm{b}}$ is the leaf boundary layer conductance, and $g_{\mathrm{s}}$ is the stomatal conductance. The photosynthesis model is coupled to the Ball-Berry stomatal conductance model (Ball et al., 1987; Collatz et al., 1991), in which stomatal conductance, $g_{\mathrm{s}}$, is calculated based on the relationship:

$g_{\mathrm{s}}=b+m A_{n} h_{\mathrm{s}} / c_{\mathrm{s}}$

where $b$ is the minimum stomatal conductance when $A_{n} \leq 0$, $m$ is the Ball-Berry slope of the conductance-photosynthesis relationship, and $h_{\mathrm{S}}$ is the fractional humidity at the leaf surface. Additional details are given in Bonan et al. (2011). The coupling of photosynthesis and stomatal conductance models results in a direct dependence of stomatal conductance on photosynthesis, while stomatal conductance plays a role in predicting photosynthesis by controlling $c_{i}$, which is obtained from the diffusion equation and therefore depends on $g_{s}$. The model is forced with specified environmental variables, with $c_{a}$ ranging from $50-2000 \mu \mathrm{mol} \mathrm{CO}_{2} \mathrm{~mol}^{-1}$ air, light ranging from $0-2000 \mu \mathrm{mol}$ photons $\mathrm{m}^{-2} \mathrm{~s}^{-1}$, temperature $=22^{\circ} \mathrm{C}, h_{\mathrm{s}}=0.70$, and $g_{\mathrm{b}}=0.05 \mathrm{~m} \mathrm{~s}^{-1}$.

\subsection{Ozone response relationships}

\subsubsection{Photosynthesis}

Two methods of simulating $\mathrm{O}_{3}$-induced decreases in photosynthesis were compared. The first method of modifying photosynthesis expanded on work by Lombardozzi et al. (2012) and is denoted here as the Psn modification. This modification mimicked observed decreases in photosynthesis using an $\mathrm{O}_{3}$ factor developed by Lombardozzi et al. (2012) based on tulip poplar responses to $\mathrm{O}_{3}, F_{A_{\mathrm{O}_{3}}}$, calculated from a linear regression of treatment to control response ratios against cumulative $\mathrm{O}_{3}$ uptake (CUO):

$F_{\mathrm{AO}_{3}}=1.0421-0.2399 \times \mathrm{CUO}$

where $F_{A_{\mathrm{O}_{3}}}$ is the response ratio of treatment to control photosynthesis, 1.0421 and 0.2399 are empirically derived intercept and slope coefficients, respectively, and CUO is the cumulative $\mathrm{O}_{3}$ uptake. The calculation for CUO assumes that the $\left[\mathrm{O}_{3}\right]$ inside the leaf is zero and is calculated as

$\mathrm{CUO}=\Sigma\left(k_{\mathrm{O}_{3}} / r_{\mathrm{s}}\right)\left[\mathrm{O}_{3}\right]$

similar to Reich (1987), Nunn et al. (2006) and Wittig et al. (2007), where $k_{\mathrm{O}_{3}}=1.67$ and is the ratio of leaf resistance to $\mathrm{O}_{3}$ to leaf resistance to water, $r_{\mathrm{s}}$ is leaf-level stomatal resistance, and $\left[\mathrm{O}_{3}\right]$ is the $\mathrm{O}_{3}$ concentration. CUO is 
summed through time, with units of $\mathrm{mmol} \mathrm{m}^{-2}$. The Psn modification occurs post hoc in which net photosynthesis, after it is calculated using the leaf photosynthesis/stomatal conductance model, is multiplied by $F_{\mathrm{A}_{3}}$. This method of modifying photosynthesis is similar to parameterizations in most other models that incorporate $\mathrm{O}_{3}$ damage to physiology (e.g. Felzer et al., 2004, 2005; Ollinger et al., 1997; Ollinger et al., 2002; Ren et al., 2011; Sitch et al., 2007).

The second method of modifying photosynthesis, denoted here as Rub, impacts the biochemical aspects of photosynthesis directly through altering the $V_{\text {cmax }}$ parameter in the Farquhar model. $V_{\text {cmax }}$ integrates mesophyllic conductance with enzyme amount and activity and therefore estimates aspects of biochemical carbon fixation that are often damaged with $\mathrm{O}_{3}$ exposure (Calatayud et al., 2010; Cardoso-Vilhena et al., 2004; Farage and Long, 1999; Feng et al., 2008; Fiscus et al., 2005; Noormets et al., 2001; Ojanpera et al., 1998; Pellegrini et al., 2010; Zheng et al., 2002). This modification mimicked observed decreases in $V_{\text {cmax }}$ using an $\mathrm{O}_{3}$ factor calculated based on tulip poplar from work by Lombardozzi et al. (2012), $F_{R_{\mathrm{O}_{3}}}$ :

$F_{R_{\mathrm{O}_{3}}}=0.9888-0.1976 \times \mathrm{CUO}$

where $F_{R_{\mathrm{O}_{3}}}$ is the response ratio of treatment to control $V_{\text {cmax }}$. The Rub modification multiplies $V_{\text {cmax }}$ by $F_{R_{\mathrm{O}_{3}}}$, using the $\mathrm{O}_{3}$-modified $V_{\text {cmax }}$ in photosynthesis calculations. This method of modifying photosynthesis through changing $V_{\text {cmax }}$ is similar to parameterizations used in Martin et al. (2000) to simulate photosynthetic responses to acute $\mathrm{O}_{3}$ exposure and Constable and Taylor (1997) to simulate chronic exposure.

\subsubsection{Stomatal conductance}

A new method of simulating $\mathrm{O}_{3}$-induced decreases in stomatal conductance by altering the $V_{\text {cmax }}$ parameter in photosynthesis calculations was compared to the Cnd modification developed by Lombardozzi et al. (2012). The Cnd modification altered stomatal conductance directly using an $\mathrm{O}_{3}$-factor based on tulip poplar responses to $\mathrm{O}_{3}$ that was calculated by Lombardozzi et al. (2012), $F_{\mathrm{Gs}_{\mathrm{O}_{3}}}$, calculated from a linear regression of treatment to control response ratios against $\mathrm{cu}-$ mulative $\mathrm{O}_{3}$ uptake (CUO):

$F_{\mathrm{Gs}_{\mathrm{O}_{3}}}=1.0884-0.1998 \times \mathrm{CUO}$

where $F_{\mathrm{Gs}_{\mathrm{O}_{3}}}$ is the response ratio of treatment to control stomatal conductance, and 1.0884 and 0.1998 are empirically derived intercept and slope coefficients, respectively. The Cnd modification multiplies stomatal conductance by $F_{\mathrm{Gs}_{3}}$ after stomatal conductance is calculated and does not alter the photosynthesis calculations in the model.

The second method of altering stomatal conductance, denoted as Rub, modified conductance indirectly using the new modification to the photosynthesis model that modified $V_{\mathrm{cmax}}$ by $F_{R_{\mathrm{O}_{3}}}$ (described above). This simulation relied on photosynthetic decreases to indirectly drive stomatal conductance decreases, similar to methods used by Martin et al. (2000) and Constable and Taylor (1997).

\subsection{Simulations}

Each photosynthesis (Psn, Rub) and stomatal conductance (Cnd, Rub) modification simulated light curves at three prescribed $\mathrm{O}_{3}$ uptake levels $\left(0,2\right.$ and $\left.4.2 \mathrm{mmol} \mathrm{m}^{-2}\right)$ based on experimental tulip poplar exposure rates by calculating photosynthesis and stomatal conductance over a range of light values from 0 through $2000 \mu \mathrm{mol} \mathrm{m}^{-2} \mathrm{~s}^{-1}$ with $\left[\mathrm{CO}_{2}\right]$ at $380 \mathrm{ppm}$ and a temperature of $25^{\circ} \mathrm{C}$. Additionally, each photosynthesis modification simulated photosynthetic responses to changing internal $\left[\mathrm{CO}_{2}\right]\left(A-c_{i}\right.$ curves $)$ at all three $\mathrm{O}_{3}$ uptake levels by calculating photosynthesis over a range of $\left[\mathrm{CO}_{2}\right]$ from 50 to $2000 \mathrm{ppm}$ with light equal to $2000 \mu \mathrm{mol} \mathrm{m}{ }^{-2} \mathrm{~s}^{-1}$ and a temperature of $25^{\circ} \mathrm{C}$. The simulated plants were individualized through changing dark respiration $\left(R_{\mathrm{d}}\right)$ rates and model parameters $V_{\mathrm{cmax}}$ and $J_{\max }$ were set to appropriate values based on measured rates for the experimental plants. The model was evaluated by comparing predictions of photosynthesis and stomatal conductance with plant responses measured in Lombardozzi et al. (2012).

\subsection{Statistical analysis}

Results of the simulations were analyzed to determine which modification allowed the model to best fit the data using $R^{\complement}$ version 2.11.1. Simulations were analyzed for root mean squared error (RMSE) to quantify the variance and mean bias (MB) to determine the magnitude and direction of the model bias. Linear mixed-effects models with plant as the random factor were fit to the experimental data using the nlme package in R (Pinheiro et al., 2012). The model with the highest likelihood was selected as the best model.

\subsection{Testing the community land model}

The CLM4SP represents biophysical land surface processes within the context of a global climate simulation model and is described in Lawrence et al. (2011). In this study, the model was run in offline mode forced with a historical atmospheric dataset that includes observed precipitation, temperature, downward solar radiation, surface windspeed, specific humidity, and air pressure from 1948 through 2004 (Qian et al., 2006). The CLM4SP uses coupled Farquhar photosynthesis and Ball-Berry stomatal conductance models (Bonan et al., 2011; Oleson et al., 2010) to simulate plant physiology.

\subsection{Ozone effects}

To incorporate the effects of $\mathrm{O}_{3}$ on photosynthesis and stomatal conductance into the CLM4SP, we used the Rub photosynthesis modification and the Cnd stomatal conductance modification to the Farquhar/Ball-Berry model, which are based on tulip poplar responses calculated by Lombardozzi 
et al. (2012). The Rub modification had the highest likelihood of accurately predicting photosynthesis through modifying the $V_{\text {cmax }}$ parameter in the model. Likewise, the Cnd modification had the highest likelihood of predicting stomatal conductance through directly modifying the conductance variable. Additionally, the Cnd modification allowed the most flexibility in simulating other situations where stomatal conductance responds independently of photosynthesis. For example, stomata sometimes respond sluggishly after chronic $\mathrm{O}_{3}$ exposure (e.g. Paoletti, 2005), so the Cnd parameterization can be used to simulate $\mathrm{O}_{3}$-induced changes in diurnal transpiration. Nighttime transpiration and damage from photo-oxidation can also be simulated using the Cnd modification.

Ozone effects on both photosynthesis and stomatal conductance were included in the CLM4SP based on the $\mathrm{O}_{3}$ response factors calculated for the Farquhar/Ball-Berry model. Cumulative $\mathrm{O}_{3}$ uptake (CUO) was calculated by the CLM4SP rather than being specified as in the leaf-level simulations. Therefore, four key differences existed in the calculations of CUO. First, CUO in the CLM was calculated using the sum of stomatal, boundary layer, and aerodynamical resistances. Second, a critical uptake threshold of $0.8 \mathrm{nmol} \mathrm{O}_{3} \mathrm{~m}^{-2} \mathrm{~s}^{-1}$ was used as an instantaneous, fluxbased threshold (similar to methods used in Sitch et al., 2007). Third, because $\mathrm{O}_{3}$ damage is cumulative, we included a leaf-turnover $\mathrm{O}_{3}$ decay rate so that accumulated $\mathrm{O}_{3}$ damage did not accrue beyond the average leaf lifetime for evergreen plants. Last, CUO was only integrated over the time when leaf area index (LAI) was above a minimum value of 0.5 . This threshold was chosen based on modeled LAI values because LAI values are often asymptote in the model rather than reaching 0 (see Fig. 1) causing $\mathrm{O}_{3}$ accumulation to be too high. For a deciduous tree species, the $0.5 \mathrm{LAI}$ threshold did not significantly change accumulated $\mathrm{O}_{3}$ damage.

\subsection{Simulations}

The primary objective of the CLM simulations was to compare direct $\mathrm{O}_{3}$ modifications to both photosynthesis and stomatal conductance (PG simulation) with indirect $\mathrm{O}_{3}$ modifications to stomatal conductance through modifying photosynthesis (Pg simulation). Since photosynthesis and stomatal conductance were inherently linked in the CLM due to the traditional Ball-Berry formulation, calculations for both variables were made three times during each simulation to allow for separation between optimal rates and $\mathrm{O}_{3}$-influenced rates. The first calculations provided optimal levels of photosynthesis $\left(\mathrm{psn}_{\mathrm{opt}}\right)$ and stomatal conductance $\left(g_{\text {sopt }}\right)$ and were calculated in the absence of $\mathrm{O}_{3}$. The second set of calculations directly modified photosynthesis $\left(\mathrm{psn}_{\mathrm{O}_{3}}\right)$ for $\mathrm{O}_{3}$ and allowed stomatal conductance $\left(g_{\mathrm{sfb}}\right)$ to respond indirectly and through feedback loops. The third set of calculations modified stomatal conductance $\left(g_{\mathrm{S}_{3}}\right)$ for $\mathrm{O}_{3}$ and allowed photosynthesis $\left(\mathrm{psn}_{\mathrm{fb}}\right)$ to respond via feedback loops. We used

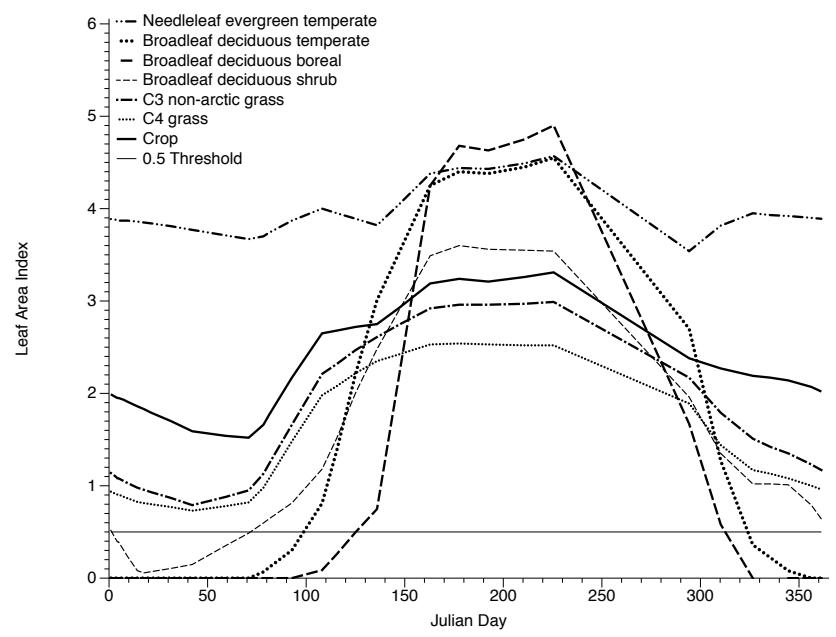

Fig. 1. Annual leaf area index (LAI) cycle for several plant functional types (PFTs) that are simulated in the CLM. The 0.5-LAI threshold (grey horizontal line), above which $\mathrm{O}_{3}$ accumulates, demonstrates that $\mathrm{O}_{3}$ accumulates at most times when LAI is positive, but minimizes uptake when LAI does not mathematically reach 0 when it should equal 0 , particularly relevant in the broadleaf deciduous temperate and boreal trees.

this parameterization to run four different experimental simulations (see Table 1) that determined the magnitude of direct and indirect responses in addition to feedback loops between photosynthesis and stomatal conductance. This verified that the indirect responses could be eliminated. Simulations were named with letters " $p$ " when photosynthesis was modified and "g" when stomatal conductance was modified, with a capital letter (e.g. P and G) signifying that the modification was direct and a lower case letter (e.g. p and g) signifying that the modification was indirect. The objective of each simulation was to determine the optimal or $\mathrm{O}_{3}$-influenced photosynthesis and stomatal conductance values to be used in the downstream calculations like GPP and transpiration. For example, to determine whether $\mathrm{O}_{3}$-modified photosynthesis could be calculated without influencing transpiration, the model used modified photosynthesis, $\mathrm{psn}_{\mathrm{O}_{3}}$, and optimal conductance, $g_{\text {sopt }}$, for all downstream calculations.

To create a new modeling framework that would allow for decoupled behavior of photosynthesis and stomatal conductance, we took several steps to test the model behavior and make differences from the control simulation large. First, all simulations were run at a constant $\mathrm{O}_{3}$ concentration of $100 \mathrm{ppb}$. This is an unrealistically high global concentration of $\mathrm{O}_{3}$, but it helped to determine whether $\mathrm{O}_{3}$ damage could be independently incorporated for photosynthesis and stomatal conductance and to identify hotspots where $\mathrm{O}_{3}$ damage might have a large impact on GPP and transpiration. Second, for simplicity all $\mathrm{O}_{3}$ modifications were based on data collected on tulip poplar seedling responses to $\mathrm{O}_{3}$ (Lombardozzi et al., 2012). Plant species-specific responses representing 
Table 1. Description of the names, variables and simulations in the CLM.

\begin{tabular}{|c|c|c|}
\hline \multicolumn{3}{|r|}{ Variables } \\
\hline Name & Variable & Description \\
\hline G & $g_{\mathrm{SO}_{3}}$ & $\mathrm{O}_{3}$ affects conductance directly \\
\hline $\mathrm{g}$ & $g_{\mathrm{sfb}}$ & $\mathrm{O}_{3}$ indirectly affects conductance due to changes in photosynthesis \\
\hline $\mathrm{P}$ & $\operatorname{psn}_{\mathrm{O}_{3}}$ & $\mathrm{O}_{3}$ affects photosynthesis directly \\
\hline $\mathrm{p}$ & $\mathrm{psn}_{\mathrm{fb}}$ & $\mathrm{O}_{3}$ indirectly affects photosynthesis due to changes in conductance \\
\hline \multicolumn{3}{|r|}{ Experimental modifications } \\
\hline $\mathrm{Pg}$ & $\mathrm{psn}_{\mathrm{O}_{3}} g_{\mathrm{sfb}}$ & $\begin{array}{l}\mathrm{O}_{3} \text { affects photosynthesis directly while indirectly changing conductance. Standard parameterization } \\
\text { used currently in models. }\end{array}$ \\
\hline$P$ & $\operatorname{psn}_{\mathrm{O}_{3}} g_{\text {sopt }}$ & $\begin{array}{l}\mathrm{O}_{3} \text { affects photosynthesis but does not change conductance because the links between photosynthesis } \\
\text { and conductance have been cut. }\end{array}$ \\
\hline G & $\operatorname{psn}_{\mathrm{opt}} g_{\mathrm{s}_{3}}$ & $\begin{array}{l}\mathrm{O}_{3} \text { affects conductance but does not change photosynthesis because the links between conductance } \\
\text { and photosynthesis have been cut. }\end{array}$ \\
\hline PG & $\operatorname{psn}_{\mathrm{O}_{3}} g_{\mathrm{s}_{\mathrm{O}_{3}}}$ & $\begin{array}{l}\mathrm{O}_{3} \text { affects conductance without indirect changes to photosynthesis and } \mathrm{O}_{3} \text { affects photosynthesis } \\
\text { without indirect changes to conductance. }\end{array}$ \\
\hline
\end{tabular}

Table 2. Statistical results calculated for the Psn, Run, and Cnd modifications to the Farquhar/Ball-Berry model. Intercept, slope, negative $\log$ likelihood, root mean square error (RMSE), and mean bias were calculated for both conductance and photosynthetic responses to varying levels of light (light curve) and photosynthetic responses to varying levels of $\mathrm{CO}_{2}\left(A-c_{i}\right.$ curve) compared to observed tulip poplar responses at $\mathrm{O}_{3}$ uptake values of 0,2 , and $4.2 \mathrm{mmol} \mathrm{m}^{-2}$. Values in bold are the modifications within the response variable selected for use in the CLM simulations and are based on lowest negative log likelihood values.

\begin{tabular}{|c|c|c|c|c|c|c|}
\hline Variable of interest & Modification name & Intercept & Slope & $\begin{array}{r}\text { Negative Log } \\
\text { likelihood }\end{array}$ & RMSE & Mean bias \\
\hline \multicolumn{7}{|c|}{$A-c_{i}$ curve } \\
\hline Photosynthesis & Psn & 2.21 & 1.07 & -312.390 & 4.34 & 2.46 \\
\hline Fig. $2 \mathrm{~g}-\mathrm{i}$ & Rub & -0.04 & 1.32 & -227.658 & 3.41 & 1.60 \\
\hline \multicolumn{7}{|c|}{ Light curve } \\
\hline Photosynthesis & Psn & 0.54 & 0.84 & -164.606 & 1.23 & 0.07 \\
\hline Fig. $2 \mathrm{~d}-\mathrm{f}$ & Rub & 0.34 & 0.89 & -158.600 & 1.22 & -0.008 \\
\hline Conductance & Psn & 0.068 & 0.39 & 201.473 & 0.054 & 0.030 \\
\hline \multirow[t]{2}{*}{ Fig. $2 a-c$} & Rub & 0.065 & 0.41 & 200.668 & 0.051 & 0.027 \\
\hline & Cnd & 0.067 & 0.34 & 198.985 & 0.051 & 0.020 \\
\hline
\end{tabular}

multiple plant functional types should be used once these data become available. Each simulation was run for a total of $25 \mathrm{yr}$, with the first $5 \mathrm{yr}$ being discarded in analyses to allow for stabilization of accumulated $\mathrm{O}_{3}$ damage.

\section{Results}

\subsection{Farquhar photosynthesis/Ball-Berry conductance model}

All stomatal conductance modifications to the Farquhar/ Ball-Berry model decreased predicted conductance with increasing $\mathrm{O}_{3}$ uptake, though the magnitudes varied (Fig. 2ac; Table 2). When comparing the ability of each modification to predict the observed conductance light curves measured in tulip poplar, changing conductance directly (the Cnd 

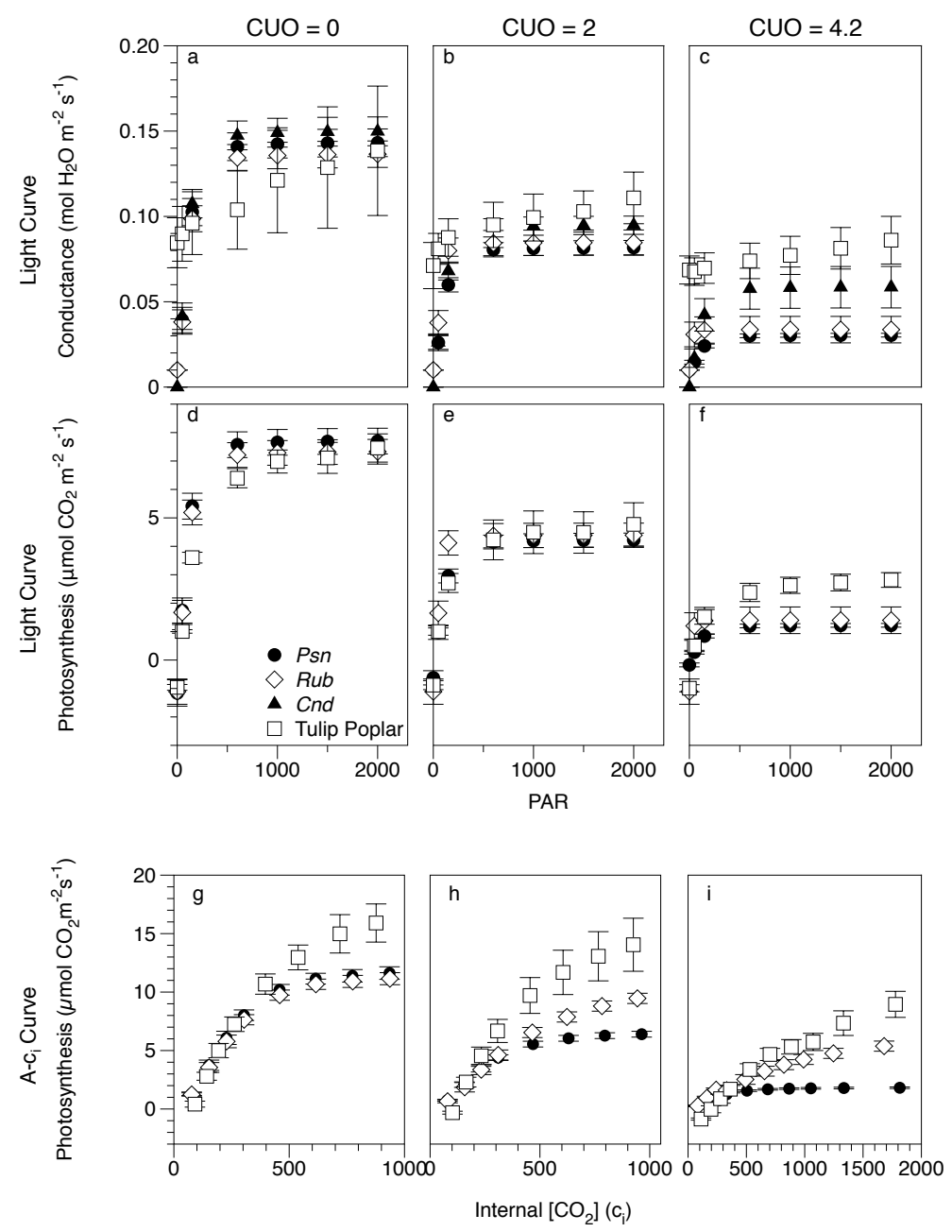

Fig. 2. Mean light and $A-c_{i}$ curves predicted by different Farquhar/Ball-Berry model parameterizations compared with observed tulip poplar responses at various cumulative $\mathrm{O}_{3}$ uptake (CUO) values. Simulations were run before the effects of $\mathrm{O}_{3}-\mathrm{CUO}=0$; (a), (d), and (g); at CUO of $2 \mathrm{mmol} \mathrm{m}^{-2}-(\mathbf{b}),(\mathbf{e})$, and (h); and at a CUO of $4.2-(\mathbf{c})$, (f), and (i). The Cnd model predicts observed stomatal conductance responses to different light values - (a)-(c) - more accurately than the Psn or Rub models. The Rub model predicts observed photosynthetic responses to light $-(\mathbf{d})-(\mathbf{f})-$ more accurately than the Psn model. Neither model predicts observed photosynthetic responses to $A-c_{i}-$ (g)-(i) - as accurately as light, though the Rub model predicts $A-c_{i}$ curves more accurately than the Psn model. Error bars represent mean standard error. See Table 2 for a description of the simulations.

modification) best predicted the observation (neg. log likelihood $=199.0$ ) and was selected for use in CLM simulations. The simulation that indirectly changed predicted conductance (the Rub modification) did not perform as well as the direct conductance changes (the Cnd modification; neg. log likelihood $=200.7$ ) and had a higher mean bias (bias $=0.027)$ compared to the simulation using the Cnd modification (bias $=0.020$ ). At low light levels, modifications predicted conductance values lower than observed conductance values. Root mean square error was the same for both simulations (Rub and Cnd RMSE $=0.051 \mu \mathrm{mol} \mathrm{CO}_{2} \mathrm{~m}^{-2} \mathrm{~s}^{-1}$ ).

Both the post-hoc photosynthesis (Psn) modification and the biochemical photosynthesis (Rub) modification decreased predicted net photosynthetic rates with increasing $\mathrm{O}_{3}$ uptake, similar to net photosynthetic rates observed in tulip poplar. Photosynthesis modifications predicted light curves more accurately than $\mathrm{A}-\mathrm{c}_{i}$ curves at all $\mathrm{O}_{3}$ uptake values (Fig. 2d-f and g-i), with mean biases for light curves close to 0 for both modifications (Psn $=0.07$; Rub $=-0.008$ ) and RMSE approximately $1.2 \mu \mathrm{mol} \mathrm{CO} \mathrm{C}^{-2} \mathrm{~s}^{-1}$. The biochemical photosynthesis (Rub) modification predicted observed tulip poplar responses to light better than the post-hoc photosynthesis (Psn) modification (Fig. 2d-f; Rub neg. log likelihood $=-158.6$; Psn neg. log likelihood $=-164.6$ ). When compared to observed tulip poplar $A-c_{i}$ curves, the biochemical photosynthesis (Rub) modification outperformed the post-hoc photosynthesis (Psn) modification at each $\mathrm{O}_{3}$ uptake value (Fig. 2g-i; Rub neg. log likelihood $=-227.658$; 


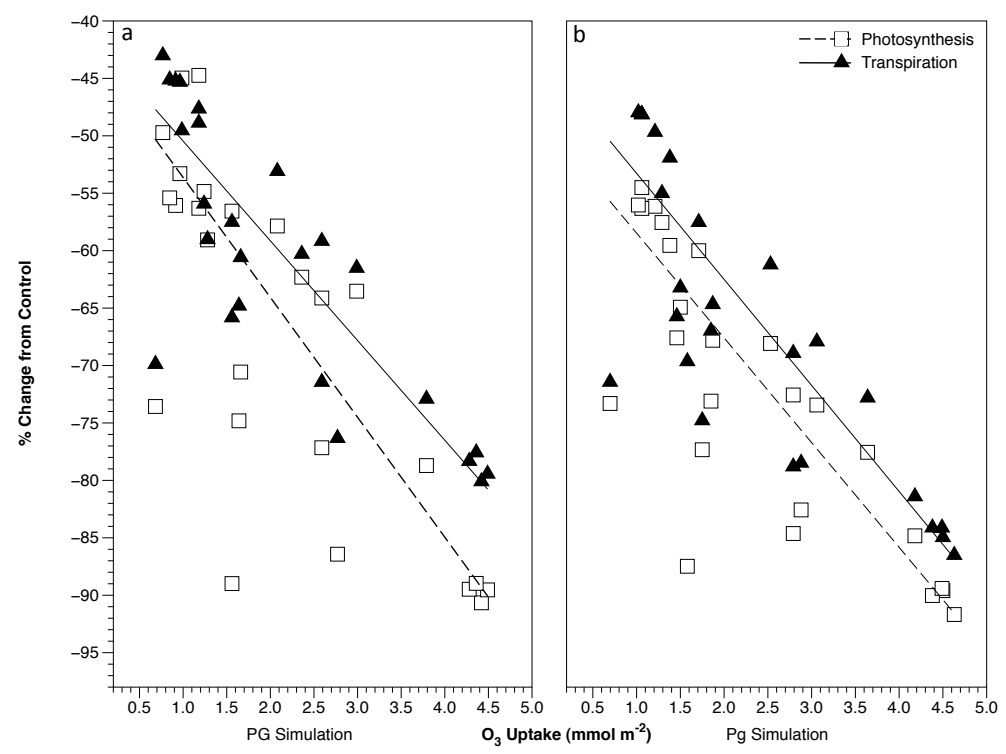

Fig. 3. Percent change from control CLM simulations in photosynthesis and transpiration over a range of $\mathrm{O}_{3}$ uptake in the PG (direct change to conductance; (a) and Pg (indirect change to conductance; (b) simulations. Results are from a $5 \times 5$ gridded region centered on Ithaca, NY (latitudes between $270-280^{\circ}$; longitudes between $38-46^{\circ}$ ) as modeled by the CLM. Points are gridcell averages from August of the 10th simulated year.

Psn neg. $\log$ likelihood $=-312.390$ ). Both modifications were positively biased, though the RMSE of the biochemical (Rub) modification was $0.93 \mu \mathrm{mol} \mathrm{CO}_{2} \mathrm{~m}^{-2} \mathrm{~s}^{-1}$ less than the post-hoc (Psn) modification. Overall, the biochemical (Rub) modification predicts photosynthesis more accurately in both $A-c_{i}$ and light curves than the Psn modification (Table 2; Fig. 2). Consequently, the biochemical (Rub) photosynthesis modification was selected for use in all CLM simulations.

\subsection{CLM simulations}

We considered first the impact of modifications of the CLM on a $5 \times 5$ grid centered on Ithaca, NY, where photosynthetic and stomatal modifications were developed. In the simulated region surrounding Ithaca, NY, transpiration and photosynthesis decreased in response to the $100 \mathrm{ppb}$ $\mathrm{O}_{3}$ exposure. When $\mathrm{O}_{3}$ directly altered photosynthesis and conductance (the PG simulation), transpiration decreased $\left(r^{2}=-0.90 ;\right.$ rate $=-8.68 \%$ per $\left.\mathrm{mmol} \mathrm{O}_{3} \mathrm{~m}^{-2}\right)$ at a slower rate than photosynthesis $\left(r^{2}=-0.89\right.$; rate $=-10.44 \%$ per $\mathrm{mmol} \mathrm{O}_{3} \mathrm{~m}^{-2}$ ) for the same $\mathrm{O}_{3}$ uptake (Fig. $3 \mathrm{a} ; p=0.19$ ). At an $\mathrm{O}_{3}$ uptake of $4 \mathrm{mmol} \mathrm{m}^{-2}$ in the simulation directly modifying conductance (the PG simulation), photosynthesis decreased by $85 \%$, whereas transpiration only decreased by $76.5 \%$. Indirect changes to conductance (the Pg simulation) resulted in more similar rates of change in photosynthesis $\left(r^{2}=-0.92\right.$; rate $=-9.12 \%$ per $\left.\mathrm{mmol} \mathrm{O}_{3} \mathrm{~m}^{-2}\right)$ and transpiration $\left(r^{2}=-0.91\right.$; rate $=-9.23 \%$ per $\mathrm{mmol} \mathrm{O}_{3} \mathrm{~m}^{-2}$; $p=0.78$ ), where photosynthesis decreased by $85.8 \%$ and transpiration decreased by $81 \%$ at an $\mathrm{O}_{3}$ uptake of $4 \mathrm{mmol}$ $\mathrm{m}^{-2}$ (Fig. 3b).
Global transpiration decreased in all simulations when $\mathrm{O}_{3}$ modifications caused decreases in stomatal conductance (Fig. 4). Modifying photosynthesis directly and conductance indirectly (the Pg simulation) caused substantially larger decreases in transpiration than directly changing photosynthesis and stomatal conductance (the PG simulation). Compared to the control simulation, transpiration rates decreased more than $50 \%$ in many areas when conductance was changed indirectly (the Pg simulation), with the largest decreases in the tropics and other regions with high control transpiration rates (Fig. 4b). In contrast, directly changing conductance (the PG simulation) produced smaller decreases in transpiration in tropical regions (Fig. 4c), typically less than 50\%, and similar decreases in mid- and high-latitudes (40-80\%). Relative differences between the simulations that changed conductance indirectly (Pg) and directly (PG; Fig. 4d) show that changing conductance directly (the PG simulation) results in higher transpiration rates - greater than $25 \%$ in most tropical regions - than predicted by changing conductance indirectly (the Pg simulation) in almost all locations. In a few temperate locations, however, the direct conductance modification (the PG simulation) caused transpiration to decrease up to $10 \%$ more than the indirect conductance modification (the Pg simulation).

Independently modifying photosynthesis and conductance in the CLM (the PG simulation) reduced the effect of $\mathrm{O}_{3}$ on GPP in regions with high control photosynthetic rates compared to direct photosynthesis and indirect conductance modifications (the Pg simulation). The Pg simulation decreased GPP in most locations, with decreases of more than $70 \%$ 

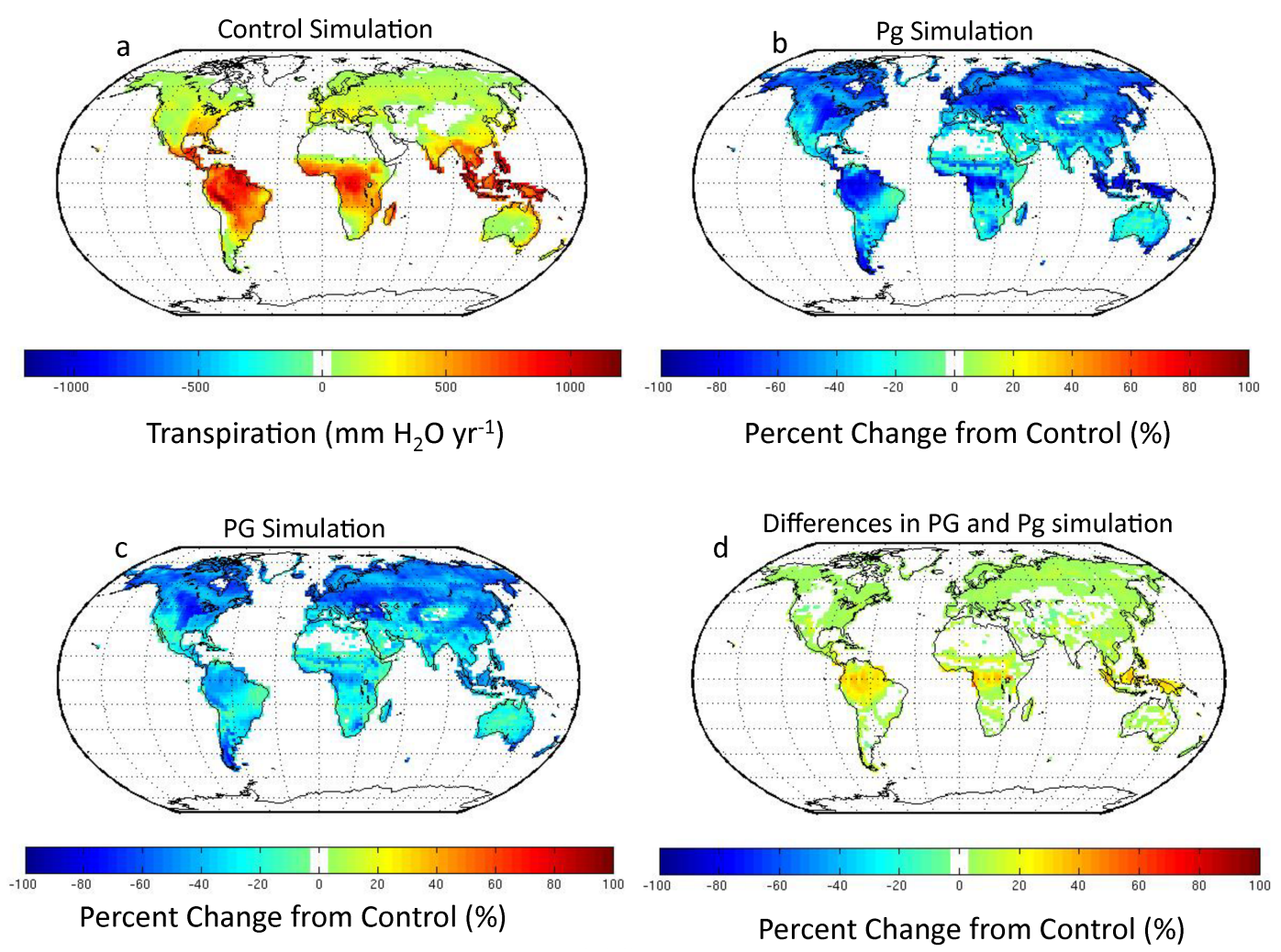

Fig. 4. Mean annual transpiration predicted in 20-yr CLM simulations run at $100 \mathrm{ppb} \mathrm{O}_{3}$. The control simulation (a) shows the average amount of water lost via transpiration annually in the absence of $\mathrm{O}_{3}$. The percent changes from control were mapped for the (b) Pg simulation, where a direct change in photosynthesis causes indirect changes in conductance and for the (c) PG simulation, where direct changes to photosynthesis and conductance occur independently. Panel (d) illustrates the differences in transpiration between the PG simulation compared to the Pg simulation, also mapped as a percent change from control.

in the tropics and high latitudes (Fig. 5b). Direct changes to photosynthesis and conductance (the PG simulation) also reduced GPP globally, though the decreases were less than $50 \%$ in most tropical regions (Fig. 5c) and the largest decreases were in the high latitudes, where GPP decreased by $50 \%$ or more from control simulations. Differences between simulations that indirectly modify conductance (the Pg simulation) and directly modify conductance (the PG simulation; Fig. 5d) demonstrate that directly modifying conductance (the PG simulation) results in GPP nearly $50 \%$ higher in the tropics than predicted by indirect conductance modifications (the Pg simulation). Differences between the PG and Pg simulations are smaller $( \pm 20 \%)$ at mid- and high- latitudes, with the simulation that directly modifies conductance (PG) resulting in both higher and lower GPP than the simulation that indirectly modifies conductance (the Pg simulation).

Directly modifying stomatal conductance (the PG simulation) in the CLM changed the rate of $\mathrm{O}_{3}$ uptake compared to indirectly modifying conductance (the Pg simulation) (Fig. 6). Average uptake rates in the simulation that indirectly modifies conductance (Pg) ranged from 1$3 \mathrm{mmol} \mathrm{m}^{-2}$ in the mid- and high-latitudes and approached $5 \mathrm{mmol} \mathrm{m}^{-2}$ in the tropics (Fig. 6a). Average $\mathrm{O}_{3}$ uptake rates in the simulation that directly modifies conductance (PG) were similar to those in the simulation that indirectly modifies conductance $(\mathrm{Pg})$ at mid- and high-latitudes, though only reached $2.5-3 \mathrm{mmol} \mathrm{m}^{-2}$ in the tropics (Fig. 6b).

Simulations that changed conductance indirectly $(\mathrm{Pg})$ and directly (PG) caused small changes in relative humidity (RH) compared to control simulations (Fig. 7) and increased relative soil moisture in many tropical, subtropical, and desert ecosystems compared to control simulations (Fig. 8). Most changes in $\mathrm{RH}$ and relative soil moisture were similar in the PG and Pg simulations. Relative humidity decreased slightly less in the tropics when conductance was directly modified (the PG simulation), resulting in a relative increase in $\mathrm{RH}$ compared to the simulation when conductance was indirectly modified (Pg; Fig. 7d). Relative soil moisture decreased by approximately $10 \%$ in isolated subtropical regions in the simulation where conductance was directly modified (PG) compared to the simulation when conductance was indirectly modified (Pg; Fig. 8d). Though RH did not change in all locations, it decreased $1-2 \%$ on average in Pg and PG simulations compared to the control simulation (Fig. $7 \mathrm{~b}$ and $\mathrm{c}$ ). However, RH increased up to $1 \%$ in Australia and in a few locations in Asia, Africa, and North America. 
While changes to stomatal conductance were implemented differently in the Pg (indirect) and PG (direct) simulations, changes made to photosynthesis were the same with differences only expected due to different $\mathrm{O}_{3}$ uptake rates. To ensure that GPP responds the same in both the Pg and PG simulations at the same $\mathrm{O}_{3}$ uptake rate, the PG and Pg simulations were forced with a constant $\mathrm{O}_{3}$ uptake rate of $3 \mathrm{mmol} \mathrm{O}_{3} \mathrm{~m}^{-2}$ (Fig. 9). Both simulations had the same $\mathrm{O}_{3}$ uptake rates (Fig. 9a) and similar GPP (Fig. 9b) in the singleyear analysis. Transpiration, however, differed between the simulations with $\pm 10 \%$ differences between the PG and Pg simulations.

To determine whether the photosynthesis and conductance modifications were truly independent, each direct parameter change was run independently without any indirect changes to the other parameter (Fig. 10). Implementing only photosynthesis modifications (the $\mathrm{P}$ simulation) had no effect on transpiration with $0 \%$ changes from control transpiration rates in all regions (Fig. 10b), though the effect on GPP was quite large, with decreases close to $100 \%$ in most locations (Fig. 10a). Implementing only stomatal conductance modifications (the $\mathrm{G}$ simulation) resulted in decreases in transpiration nearly identical to the simulation that directly modified photosynthesis and conductance (the PG simulation), with decreases up to approximately $50 \%$ in the tropics (Fig. 10d). Modifying only conductance (the $\mathrm{G}$ simulation) also changed GPP in some locations, causing decreases from control GPP that were less than $15 \%$ and increases in other locations up to $30 \%$, though there were almost no changes in GPP in tropical locales.

\section{Discussion}

Many land surface components of climate models, such as the CLM, use the coupled Farquhar/Ball-Berry model to predict photosynthesis and stomatal conductance, which are then scaled to tree, canopy, ecosystem or global areas. However, changing photosynthesis in response to chronic $\mathrm{O}_{3}$ exposure within the current Farquhar/Ball-Berry formulation does not accurately represent changes in stomatal conductance. Even small errors in stomatal conductance, when scaled to ecosystem or global areas, can propagate large errors in transpiration that then impact climate. Despite this fact, most studies modeling regional and global responses to $\mathrm{O}_{3}$ (e.g. Felzer et al., 2004, 2005; Ollinger et al., 1997, 2002; Ren et al., 2011; Sitch et al., 2007) focus primarily on changes in carbon and do not verify the accuracy of stomatal conductance predictions.

Implementing stomatal conductance responses to $\mathrm{O}_{3}$ independently of photosynthetic responses (the Cnd modification) improved the ability of the coupled Farquhar/Ball-Berry model to predict observed tulip poplar conductance values (Table 2; Fig. 2). This is different than the results of Martin et al. (2000), which found that altering $V_{\text {cmax }}$ accurately predicted conductance. However, the simulations in Martin et al. (2000) were based on responses of wheat to acute, rather than chronic, $\mathrm{O}_{3}$ exposure where conductance and photosynthesis decreased at similar rates in response to high $\left[\mathrm{O}_{3}\right]$ over a short period of time. Since chronic $\mathrm{O}_{3}$ exposure often causes conductance and photosynthesis to decrease at different rates (Calatayud et al., 2007; Gregg et al., 2006; Francini et al., 2007; Matyssek et al., 1991; Maurer et al., 1997; Mikkelsen, 1995; Novak et al., 2005; Paoletti and Grulke, 2005; Soldatini et al., 1998; Tjoelker et al., 1995), as it did in the tulip poplar trees used to parameterize these simulations, the ability of a direct conductance modification (Cnd) to improve the model was expected. The parameters in this modification can be adjusted to capture different responses based on the type of plant being simulated, including plants that increase stomatal conductance and transpiration in response to $\mathrm{O}_{3}$ exposure (Freersmith and Dobson, 1989; Maier-Maercker and Koch, 1991; Manes et al., 2001, 1998; McLaughlin et al., 2007; Mills et al., 2009).

The biochemical photosynthesis (Rub) modification to the coupled Ball-Berry/Farquhar model, which modified the $V_{\text {cmax }}$ parameter within the photosynthesis equation, improved the ability of the model to predict photosynthetic responses to internal $\mathrm{CO}_{2}\left(A-c_{i}\right)$ and light curves compared to a post-hoc photosynthesis (Psn) modification (Table 2, Fig. 2). Applying a post hoc decrease to the photosynthesis value (i.e. the Psn modification) is the method used in most models that incorporate the effects of $\mathrm{O}_{3}$ on photosynthesis (Felzer et al., 2004; Ollinger et al., 1997; Sitch et al., 2007). While this method did predict decreases in photosynthesis, the biochemical photosynthesis (Rub) modification is more representative of physiological responses to $\mathrm{O}_{3}$ because it alters the biochemical aspects of photosynthesis directly, and therefore more accurately predicts photosynthesis over a range of environmental conditions.

Accounting for direct, independent $\mathrm{O}_{3}$ damage to photosynthesis and stomatal conductance improves the accuracy of stomatal conductance predictions in the Farquhar photosynthesis/Ball-Berry stomatal conductance model and this method is, therefore, more appropriate for use in the CLM. The objective of the CLM simulations presented here was to determine the magnitude of change in GPP and transpiration between direct modifications to stomatal conductance and indirect modifications driven by photosynthesis using simulations run at $\left[\mathrm{O}_{3}\right]$ of $100 \mathrm{ppb}$ and parameterized on tulip poplar. These simulations are not detailed depictions of global responses to $\mathrm{O}_{3}$ because they do not include responses from a full array of plant functional types or continuous atmospheric $\left[\mathrm{O}_{3}\right]$. However, they do demonstrate the differences in GPP and transpiration that may occur based on the parameterization used to estimate stomatal conductance.

Allowing conductance to change independently of photosynthesis in the CLM (the PG simulation) caused transpiration to decrease at a slower rate than photosynthesis for the same $\mathrm{O}_{3}$ uptake. This trend was most clear when focused 

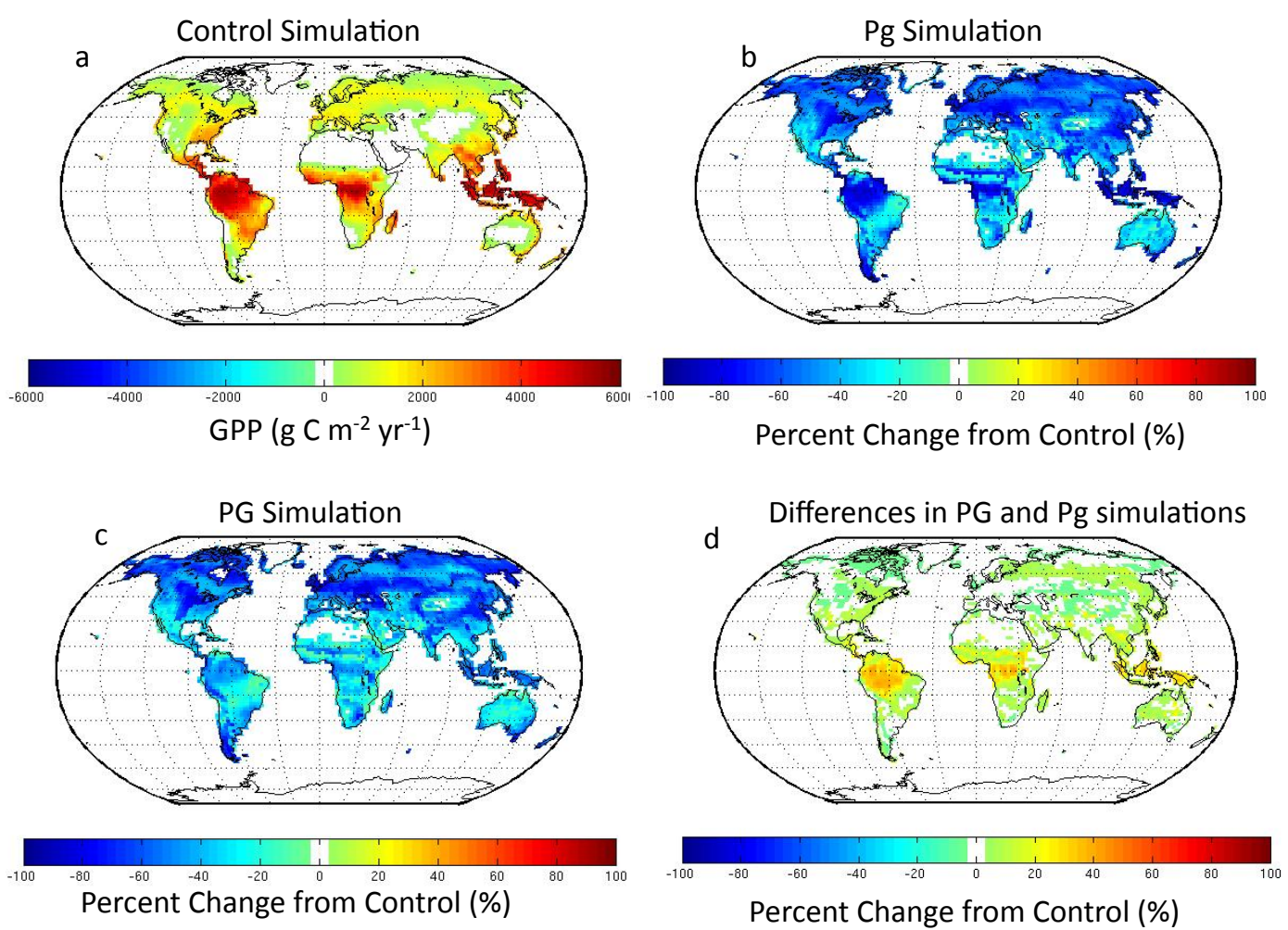

Fig. 5. Mean annual gross primary productivity (GPP) predicted in 20-yr CLM simulations run at $100 \mathrm{ppb} \mathrm{O}_{3}$. The control simulation (a) shows the average amount of carbon gained via photosynthesis annually in the absence of $\mathrm{O}_{3}$. The percent changes from control were mapped for the (b) Pg simulation, where a direct change in photosynthesis causes changes in conductance and for the (c) PG simulation, where direct changes to photosynthesis and conductance occur independently. Panel (d) illustrates the differences in GPP between the PG compared to the Pg simulation, also mapped as a percent change from control.
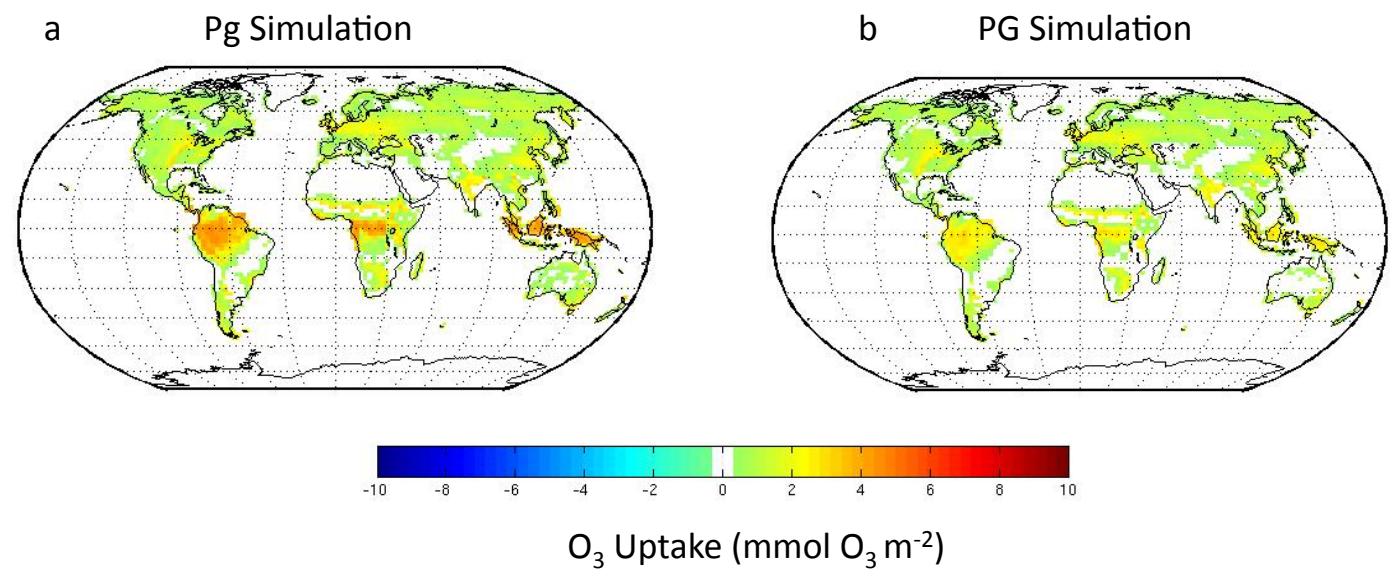

Fig. 6. Mean annual $\mathrm{O}_{3}$ uptake predicted in 20-yr CLM simulations run at $100 \mathrm{ppb} \mathrm{O}_{3}$ in the (a) $\mathrm{Pg}$ simulation, where a direct change in photosynthesis causes changes in conductance and for the (b) PG simulation, where direct changes to photosynthesis and conductance occur independently. Ozone uptake is calculated as a function of $\mathrm{O}_{3}$ concentration and stomatal conductance integrated over time.

on the $5 \times 5$ grid centered on Ithaca, NY, where the photosynthetic and stomatal modifications were developed. In this region, transpiration decreased less than photosynthesis when conductance was directly modified (the PG simulation; Fig. 3), similar to experimental observations that demonstrate larger decreases in photosynthesis than conductance in deciduous trees exposed to chronic $\mathrm{O}_{3}$ (Calatayud et al., 2007; Francini et al., 2007; Maurer et al., 1997; Mikkelsen, 1995; Novak et al., 2005; Paoletti and Grulke, 2005; Soldatini et al., 1998; Tjoelker et al., 1995). 

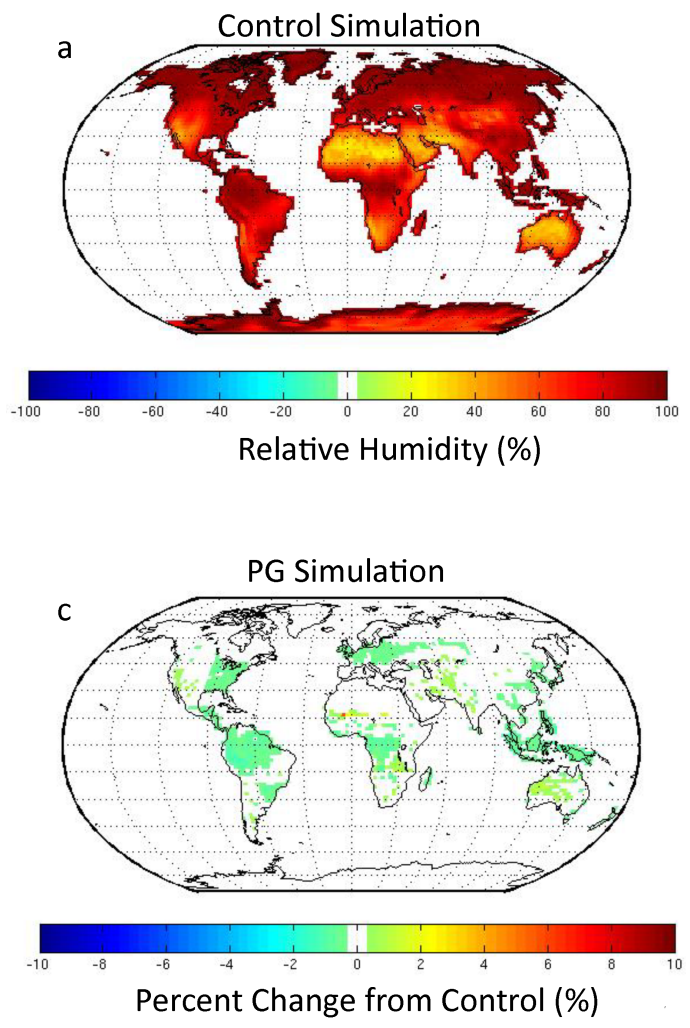

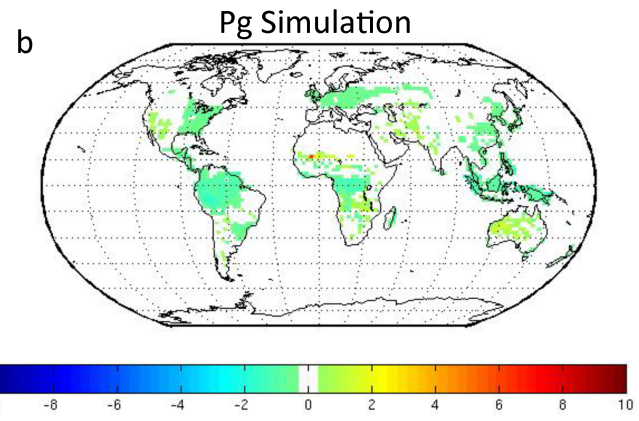

Percent Change from Control (\%)

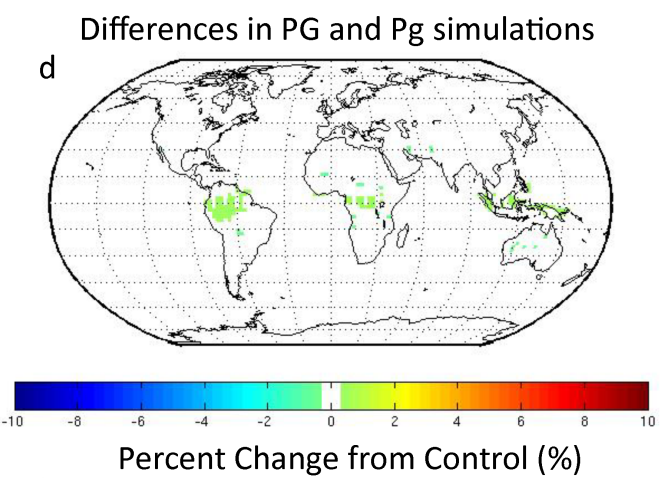

Fig. 7. Mean annual relative humidity $(\mathrm{RH})$ predicted in 20 -yr CLM simulations run at $100 \mathrm{ppb} \mathrm{O}_{3}$. The control simulation (a) shows the average $\mathrm{RH}$ annually in the absence of $\mathrm{O}_{3}$. The percent changes from control were mapped for the (b) Pg simulation, where a direct change in photosynthesis causes changes in conductance and for the (c) PG simulation, where direct changes to photosynthesis and conductance occur independently. Panel (d) illustrates the differences in RH between the PG compared to the Pg simulation, also mapped as a percent change from control. Note the difference in the scale of panels (b)-(d) compared to previous figures.

When changes in conductance were driven by photosynthetic changes (the Pg simulation), similar to most other model parameterizations, photosynthesis and transpiration had similar rates of decrease. Similarly, simulations using the TREGRO model found that photosynthesis and transpiration decreased at comparable rates when stomatal conductance was modified based on photosynthetic responses to $\mathrm{O}_{3}$ exposure (Constable and Taylor, 1997). The similar rates of decrease in photosynthesis and transpiration in these models, however, do not represent changes measured in many $\mathrm{O}_{3}$-exposure experiments. Maier-Maercker (1997) and McLaughlin et al. (2007), for example, found that transpiration increased in trees exposed to elevated $\mathrm{O}_{3}$, opposite of typical photosynthetic responses. Several studies similarly determined that photosynthesis decreases more than stomatal conductance, the primary plant control over transpiration, in response to $\mathrm{O}_{3}$, uncoupling stomatal conductance from photosynthesis (Calatayud et al., 2007; Francini et al., 2007; Novak et al., 2005). The similar rates of decrease in photosynthesis and transpiration when conductance was indirectly modified (the Pg simulation) do not match these experimental results suggesting that changing only photosynthesis likely over-predicts decreases in transpiration, and is therefore not accurately capturing changes in atmospheric water vapor, a key greenhouse gas.

On regional and global scales, $\mathrm{O}_{3}$ can have large impacts on hydrology and atmospheric water vapor by changing transpiration rates. In one of the few studies examining how hydrology responds to chronic $\mathrm{O}_{3}$, Felzer et al. (2009) found that $\mathrm{O}_{3}$, when coupled with nitrogen limitation, had a larger effect on runoff than did elevated $\mathrm{CO}_{2}$ highlighting the importance of $\mathrm{O}_{3}$ in the hydrologic cycle. The parameterization of TEM-Hydro used by Felzer et al. (2009) was similar to the $\mathrm{Pg}$ simulation in the CLM, where $\mathrm{O}_{3}$ caused decreases in conductance indirectly through reduced photosynthesis. Because nitrogen limitation reduces photosynthesis, simulations that couple photosynthetic and stomatal responses to $\mathrm{O}_{3}$, such as Felzer et al.'s (2009) parameterization of TEMHydro and the Pg simulation used in this study, can result in lower stomatal conductance rates that can increase runoff as a result of both $\mathrm{O}_{3}$ damage and nitrogen limitation. Nitrogen limitation might also decrease stomatal conductance in the parameterization that allows conductance to respond independently of photosynthesis (the PG simulation), though the effect will likely be smaller because $\mathrm{O}_{3}$ damage to conductance is not as severe. While nitrogen dynamics are important 

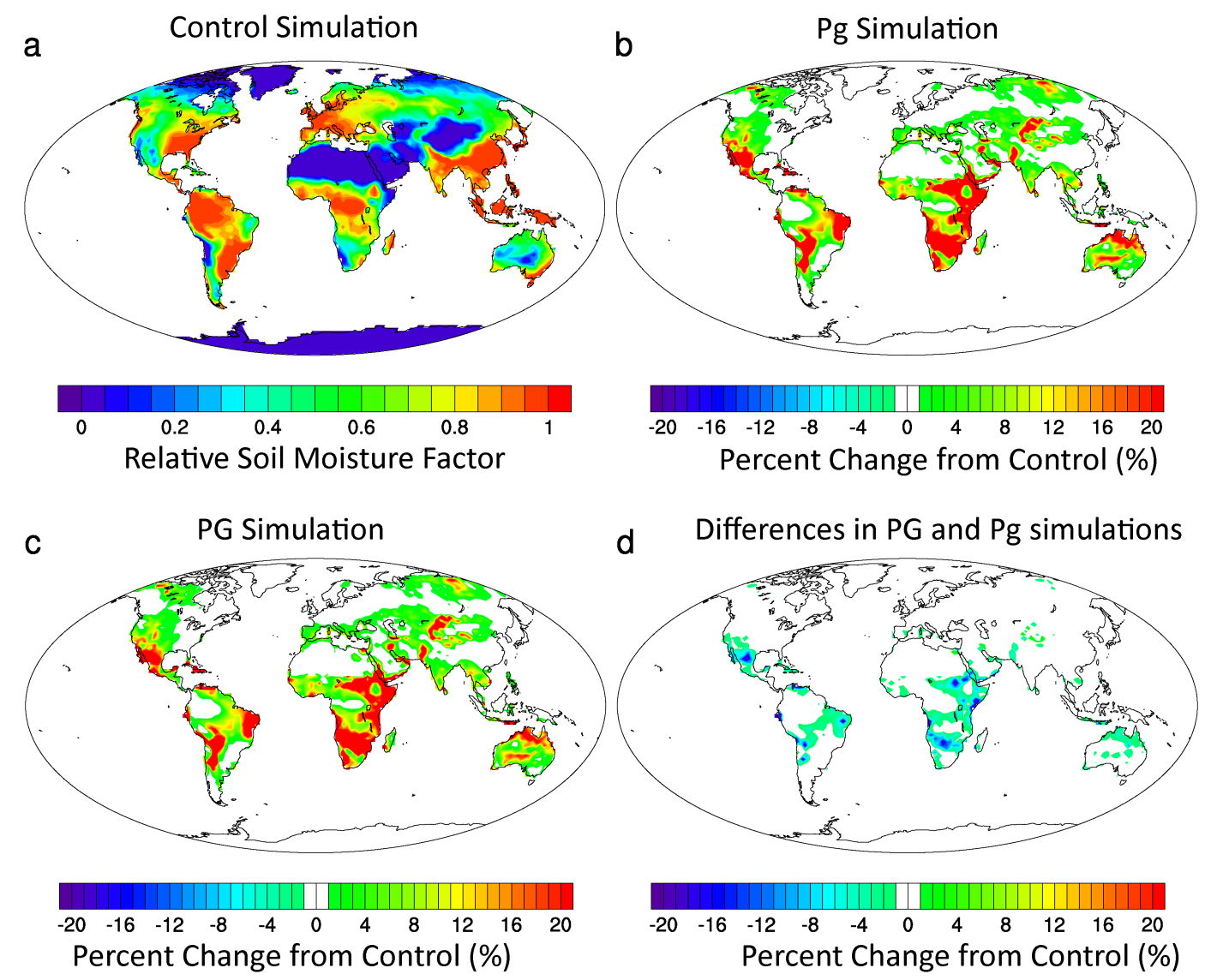

Fig. 8. Mean relative soil moisture factor predicted in 20 -yr CLM simulations run at $100 \mathrm{ppb} \mathrm{O}_{3}$. The control simulation (a) shows the average relative soil moisture factor in the absence of $\mathrm{O}_{3}$ on a scale of 0 (driest) to 1 (wettest). The percent changes from control were mapped for the (b) Pg simulation, where a direct change in photosynthesis causes changes in conductance and for the (c) PG simulation, where direct changes to photosynthesis and conductance occur independently. Panel (d) illustrates the differences in relative soil moisture between the PG compared to the Pg simulation, also mapped as a percent change from control.

to consider, the accuracy of predicted hydrology should first be improved by directly modifying stomatal conductance in response to $\mathrm{O}_{3}$ exposure.

Independently incorporating $\mathrm{O}_{3}$-induced decreases in photosynthesis and stomatal conductance (PG simulation) into the CLM yielded higher transpiration compared to simulations where photosynthesis indirectly changed stomatal conductance (Pg simulation; Fig. 4). Higher transpiration rates in the simulation that directly modified conductance (PG) were expected because stomatal conductance decreased at a slower rate than photosynthesis, which drove stomatal decreases in the simulation that indirectly modified conductance (Pg). Unsurprisingly, the differences driven by changing conductance directly compared to indirectly were particularly evident in regions with high photosynthetic rates, such as tropical latitudes where indirect changes (the Pg simulation) drove decreases in transpiration that were $30 \%$ larger than direct changes (the PG simulation). Estimates of atmospheric water vapor are therefore largely underestimated in these regions. The largest transpiration decreases in the simulation that directly changed conductance (PG) occurred in the mid-to high latitudes of the northern hemisphere and were similar in magnitude in the simulation that indirectly changed conductance $(\mathrm{Pg})$.

The water released into the atmosphere through plant transpiration is acquired from the soil. Since transpiration decreased in both the Pg and PG simulations in response to $\mathrm{O}_{3}$, it was expected that more water would remain in the soil, similar to the increased runoff found by Felzer et al. (2009). As expected, relative soil moisture increased in both $\mathrm{Pg}$ and PG simulations (Fig. 8). The increases in soil moisture in tropical, subtropical and desert ecosystems that result from decreases in transpiration suggest that seasonal drought stress might change in these regions. Though larger increases were expected in the simulation that modified conductance indirectly $(\mathrm{Pg})$, the increases in relative soil moisture were similar in both simulations. In a few isolated subtropical and desert ecosystems, there were larger relative decreases in the simulation where conductance was modified independently 

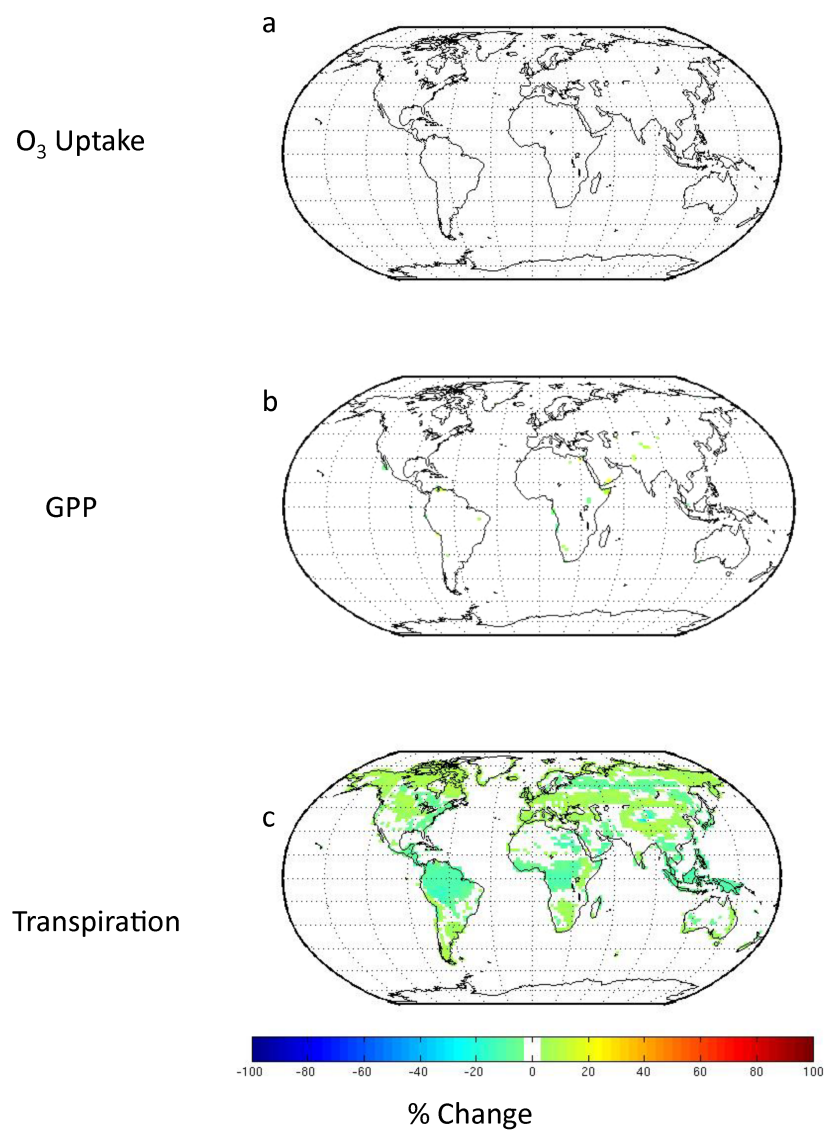

Fig. 9. A sensitivity analysis comparing the PG and Pg simulations at the same $\mathrm{O}_{3}$ uptake rate. The differences in $\mathrm{O}_{3}$ uptake (a), GPP (b), and transpiration (c) between the PG compared to the Pg simulation, mapped as a percent change from control in panels (b) and (c). Annual means were calculated from a single-year CLM simulation where $\mathrm{O}_{3}$ uptake was set at a constant rate of $3 \mathrm{mmol} \mathrm{m}^{-2}$.

(PG) due to the relatively higher transpiration rates compared to the simulation that modified conductance indirectly $(\mathrm{Pg})$.

Though photosynthesis modifications were identical in the PG and Pg simulations, GPP was typically higher in the simulation that directly modified conductance (PG; Fig. 5) suggesting that differences in conductance changed the rate of $\mathrm{O}_{3}$ uptake or altered the rate of carbon acquisition through changing $\mathrm{c}_{i}$. Ollinger et al. (1997), using PnET to determine the impacts of $\mathrm{O}_{3}$ on NPP in the northeastern United States, ran a sensitivity analysis in which $\mathrm{O}_{3}$ caused conductance to increase, rather than decrease. In this sensitivity analysis, increasing conductance resulted in higher $\mathrm{O}_{3}$ uptake, doubling the decrease in NPP. Similarly, we expected that the slower decrease in conductance due to a direct modification (the PG simulation) compared to an indirect modification (the Pg simulation) would result in higher $\mathrm{O}_{3}$ uptake rates, causing GPP to decrease more in the simulation that directly modified conductance (PG). However, $\mathrm{O}_{3}$ uptake was higher in simulations that indirectly modified conductance (the $\mathrm{Pg}$ simulation) compared to simulations that directly modified conductance (the PG simulation; Fig. 6) and caused larger decreases in GPP, opposite of expected results. Though the differences were most striking in tropical latitudes, small increases and decreases $\left( \pm 10 \mathrm{~g} \mathrm{C} \mathrm{m}^{-2} \mathrm{yr}^{-1}\right)$ in GPP were also observed in mid- and high-latitudes in the PG compared to the Pg simulation.

We conducted a sensitivity analysis to determine whether $\mathrm{O}_{3}$ uptake was driving the differences in GPP. When the $\mathrm{Pg}$ and $\mathrm{PG}$ simulations were forced at a constant $\mathrm{O}_{3}$ uptake, oneyear averages demonstrated no differences in $\mathrm{O}_{3}$ uptake, and almost no differences in GPP (Fig. 9a-b), though transpiration did change due to different methods of modifying stomatal conductance (Fig. 9c). The similarity of GPP in both simulations at the same $\mathrm{O}_{3}$ uptake suggest that the difference in $\mathrm{O}_{3}$ uptake, which was unexpectedly higher in the simulation that indirectly modified conductance $(\mathrm{Pg})$, was the primary factor driving larger decreases in GPP in the simulation that indirectly modified conductance $(\mathrm{Pg})$. Because conductance limits $\mathrm{O}_{3}$ uptake, the lower conductance rates in the simulation that directly modified conductance (PG) result in lower $\mathrm{O}_{3}$ uptake, ultimately causing differences in GPP between the PG and Pg simulations.

Relative humidity $(\mathrm{RH})$ is a factor that could be strongly related to $\mathrm{O}_{3}$ uptake in the simulations because both factors directly or indirectly influence leaf conductance and therefore potentially influence each other. For example, differences in stomatal conductance and transpiration caused by $\mathrm{O}_{3}$ uptake could potentially force changes in $\mathrm{RH}$, initiating a positive feedback cycle among stomatal conductance, transpiration and $\mathrm{RH}$ that could lead to divergence in $\mathrm{O}_{3}$ uptake between the PG and Pg simulations. In both simulations, relative humidity changed in a range of locations, but those changes were small, within $2 \%$ of RH in control simulations (Fig. 7). Further, there were only small differences between the two simulations in a few tropical locales, with RH increasing in the simulation that directly modified conductance (PG) compared to the simulation that indirectly modified conductance $(\mathrm{Pg})$ by only $1 \%$. Given the small differences between the two simulations, changes in RH were likely not driving the larger differences in $\mathrm{O}_{3}$ uptake observed in the tropics.

Photosynthesis and stomatal conductance modifications were run singly to determine the magnitude of feedbacks each modification caused. For example, stomatal conductance determines $c_{i}$, which is used in photosynthesis calculations. We therefore expected that changing only stomatal conductance ( $\mathrm{G}$ simulation) would decrease photosynthesis due to feedbacks caused by a decrease in $c_{i}$ values when conductance decreased. The G and the PG simulation decreased transpiration by the same amount because the stomatal conductance modifications were identical. However, the simulation that changed only conductance (G) caused GPP to increase relative to control simulations by $20 \%$ in many 

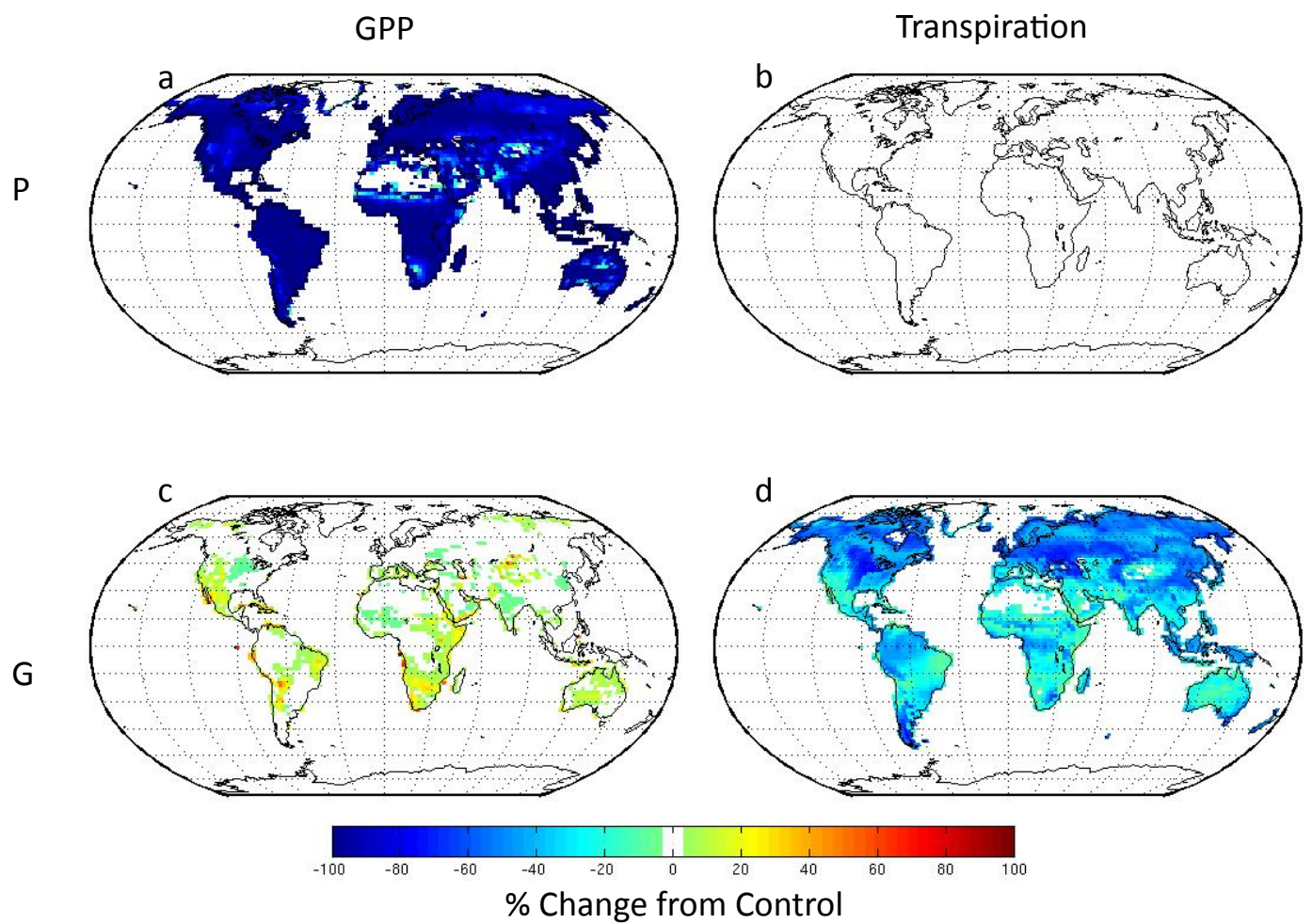

Fig. 10. Mean annual GPP and transpiration predicted in 20-yr CLM simulations run at $100 \mathrm{ppb} \mathrm{O}_{3}$. Percent differences from control were mapped for the P simulation - (a)-(b), where a direct change in photosynthesis caused decreases in GPP but did not cause indirect changes in conductance, and for the G simulation - (c)-(d), where a direct change in conductance caused decreases in transpiration and only affects photosynthesis through feedback loops.

locations, though GPP remained unchanged in the tropics and decreased in parts of North America, Africa, and Asia (Fig. 10c-d). It appears that reductions in conductance stimulate photosynthesis compared to control simulations in several locations due to feedbacks related to the leaf environment. The stimulation of photosynthesis in the simulation that changes only conductance $(\mathrm{G})$ helps explain why GPP increases in the simulation that modifies conductance directly $(\mathrm{PG})$ compared to the simulation that modified conductance indirectly $(\mathrm{Pg})$. When only photosynthesis was modified ( $\mathrm{P}$ simulation), stomata did not close in response to increasing $\mathrm{O}_{3}$, resulting in extremely large $\mathrm{O}_{3}$ uptake and corresponding decreases in photosynthesis (Fig. 10a). Transpiration did not change from control simulations (Fig. 10b) in the simulation that modified only photosynthesis $(\mathrm{P})$, suggesting that this method of modifying photosynthesis did not create any feedbacks that altered conductance.

A key finding in these simulations was that declines in GPP and transpiration were highest in tropical latitudes, similar to the findings in Sitch et al. (2007). Additionally, different methods of incorporating reductions in stomatal conductance in the Pg and PG simulations resulted in the largest differences in the tropics. Despite these large predicted changes in the tropics, very little experimental data documenting the physiological responses of tropical plants to chronic $\mathrm{O}_{3}$ exposure exists, making it difficult to determine the accuracy of responses. Though $\left[\mathrm{O}_{3}\right]$ are typically lower in tropical regions compared to mid-latitudes, the predicted sensitivity of tropical plants found both in this study and by Sitch et al. (2007) suggests that small changes in $\left[\mathrm{O}_{3}\right]$ might have large impacts in these regions, highlighting the critical research need for gas exchange data from tropical plants.

Though photosynthetic and stomatal response data are available in peer-reviewed literature and is collated in several meta-analyses (Feng et al., 2008; Morgan et al., 2003; Wittig et al., 2007), data can only be used in models if the responses are correlated with an index of exposure to $\mathrm{O}_{3}$, such as cumulative $\mathrm{O}_{3}$ uptake used in this manuscript. A few studies have calculated response relationships between photosynthesis and cumulative $\mathrm{O}_{3}$ uptake for multiple plant species (e.g. Wittig et al., 2007; Reich, 1987; Pleijel et al., 2004; Karrlson et al., 2004), but data are only available for temperate conifer and deciduous trees and crops. Further, data documenting responses of stomatal conductance to cumulative $\mathrm{O}_{3}$ uptake are almost non-existent. Most regional and global models (e.g. Felzer et al., 2004; Sitch et al., 2007) are therefore forced to parameterize photosynthetic responses to $\mathrm{O}_{3}$ based on a few species of temperate trees and crops and must assume that stomatal responses are coupled to photosynthetic responses. Ideally, data in future experiments will document 
responses of both photosynthesis and stomatal conductance to cumulative $\mathrm{O}_{3}$ uptake in plant types that span the 15 plant functional types included in the CLM. Until then, simulations that include stomatal conductance responses to $\mathrm{O}_{3}$ that are independent of photosynthesis must use the limited data that are available.

The ability of transpiration to respond differently than photosynthesis in the simulation that directly modifies conductance (PG) demonstrates that global models can allow for independent responses in photosynthesis and conductance, and we therefore recommend using this new parameterization in future models. While this work focuses on $\mathrm{O}_{3}$ oxidation damage, allowing photosynthesis and conductance to respond independently is critical for any situation that causes decoupling in these two parameters, such as oxidative damage caused by excessive light or nighttime transpiration. Though the parameterization of the CLM in these simulations is based on a single species at a single $\mathrm{O}_{3}$ concentration, responses of multiple types of plants to realistic atmospheric $\mathrm{O}_{3}$ can be incorporated into future simulations now that there is an established framework for varying photosynthesis and conductance separately. Ultimately, improving the ability of models to predict conductance allows for more accurate predictions of the water cycle, including atmospheric water vapor, a key gas in regulating climate.

Acknowledgements. The Cornell NSF Interdisciplinary Graduate Education, Research, and Training (IGERT) in Biogeochemistry and Environmental Biocomplexity provided funding for this study. Many thanks to Natalie Mahowald, Peter Hess, and Christine Goodale for helpful comments and insights in preparing this manuscript and to Keith Oleson, Joseph Simonis, Ben Dalziel for analytical advice.

Edited by: P. Stoy

\section{References}

Ball, J. T., Woodrow, I. E., and Berry, J. A.: A model predicting stomatal conductance and its contribution to the control of photosynthesis under different environmental conditions, in: Progress in photosynthesis research, edited by: Biggins, J., vol. 4, Martinus Nijhoff, The Netherlands, 221-224, 1987.

Bonan, G. B.: Forests and climate change: Forcings, feedbacks, and the climate benefits of forests, Science, 320, 1444-1449, 2008.

Bonan, G. B., Lawrence, P. J., Oleson, K. W., Levis, S., Jung, M., Reichstein, M., Lawrence, D. M., and Swenson, S. C.: Improving canopy processes in the Community Land Model version 4 (CLM4) using global flux fields empirically inferred from fluxnet data, J. Geophys. Res.-Biogeo., 116, G02014, doi:10.1029/2010JG001593, 2011.

Caird, M. A., Richards, J. H., and Donovan, L. A.: Nighttime stomatal conductance and transpiration in $\mathrm{C}_{3}$ and $\mathrm{C}_{4}$ plants, Plant Physiol., 143, 4-10, 2007.
Calatayud, V., Cervero, J., and Sanz, M. J.: Foliar, physiologial and growth responses of four maple species exposed to ozone, Water Air Soil Poll., 185, 239-254, 2007.

Calatayud, V., Marco, F., Cervero, J., Sanchez-Pena, G., and Sanz, M. J.: Contrasting ozone sensitivity in related evergreen and deciduous shrubs, Environ. Poll., 158, 3580-3587, 2010.

Cardoso-Vilhena, J., Balaguer, L., Eamus, D., Ollerenshaw, J., and Barnes, J.: Mechanisms underlying the amelioration of $\mathrm{O}_{3}{ }^{-}$ induced damage by elevated atmospheric concentrations of $\mathrm{CO}_{2}$, J. Exp. Bot., 55, 771-781, 2004.

Collatz, G., Ribas-Carbo, M., and Berry, J.: Coupled photosynthesis-stomatal conductance model for leaves of C 4 plants, Aust. J. Plant Physiol., 19, 519-538, 1992.

Collatz, G. J., Ball, J. T., Grivet, C., and Berry, J. A.: Physiological and environmental-regulation of stomatal conductance, photosynthesis and transpiration - a model that includes a laminar boundary layer, Agr. Forest Meteorol., 54, 107-136, 1991.

Constable, J. and Taylor, G.: Modeling the effects of elevated tropospheric $\mathrm{O}_{3}$ on two varieties of Pinus ponderosa, Can. J. Forest Res., 27, 527-537, 1997.

Cowan, I. and Troughto, J.: Relative role of stomata in transpiration and assimilation, Planta, 97, 325-336, 1971.

Demmig-Adams, B. and Adams, W. W.: Photoprotection in an ecological context: The remarkable complexity of thermal energy dissipation, New Phytol., 172, 11-21, 2006.

Farage, P., Long, S., Lechner, E., and Baker, N.: The sequence of change within the photosynthetic apparatus of wheat following short-term exposure to ozone, Plant Physiol., 95, 529-535, 1991.

Farage, P. K. and Long, S. P.: The effects of $\mathrm{O}_{3}$ fumigation during leaf development on photosynthesis of wheat and pea: An in vivo analysis, Photosynth. Res., 59, 1-7, 1999.

Farquhar, G., Caemmerer, S., and Berry, J.: A biochemical-model of photosynthetic $\mathrm{CO}_{2}$ assimilation in leaves of $\mathrm{C}_{3}$ species, Planta, 149, 78-90, 1980.

Felzer, B., Kicklighter, D., Melillo, J., Wang, C., Zhuang, Q., and Prinn, R.: Effects of ozone on net primary production and carbon sequestration in the conterminous united states using a biogeochemistry model, Tellus B, 56, 230-248, 2004.

Felzer, B., Reilly, J., Melillo, J., Kicklighter, D., Sarofim, M., Wang, C., Prinn, R., and Zhuang, Q.: Future effects of ozone on carbon sequestration and climate change policy using a global biogeochemical model, Climatic Change, 73, 345-373, 2005.

Felzer, B. S., Cronin, T. W., Melillo, J. M., Kicklighter, D. W., and Schlosser, C. A.: Importance of carbon-nitrogen interactions and ozone on ecosystem hydrology during the 21 st century, J. Geophys. Res. 114, G01020, doi:10.1029/2008JG000826, 2009.

Feng, Z., Kobayashi, K., and Ainsworth, E. A.: Impact of elevated ozone concentration on growth, physiology, and yield of wheat (Triticum aestivum 1.): A meta-analysis, Global Change Biol., 14, 2696-2708, 2008.

Fiscus, E., Booker, F., and Burkey, K.: Crop responses to ozone: Uptake, modes of action, carbon assimilation and partitioning, Plant Cell Environ., 28, 997-1011, 2005.

Francini, A., Nali, C., Picchi, V., and Lorenzini, G.: Metabolic changes in white clover clones exposed to ozone, Environ. Exp. Bot., 60, 11-19, 2007.

Freersmith, P. H. and Dobson, M. C.: Ozone flux to Picea sitchensis (bong) carr and Picea abies (1) karst during short episodes and the effects of these on transpiration and photosynthesis, Environ. 
Poll., 59, 161-176, 1989.

Gregg, J., Jones, C., and Dawson, T.: Physiological and developmental effects of $\mathrm{O}_{3}$ on cottonwood growth in urban and rural sites, Ecol. Appl., 16, 2368-2381, 2006.

Harley, P. and Sharkey, T.: An improved model of $\mathrm{C}_{3}$ photosynthesis at high $\mathrm{CO}_{2}$-reversed $\mathrm{O}_{2}$ sensitivity explained by lack of glycerate reentry into the chloroplast, Photosynth. Res., 27, 169178, 1991.

Harley, P., Thomas, R., Reynolds, J., and Strain, B.: Modeling photosynthesis of cotton grown in elevated $\mathrm{CO}_{2}$, Plant Cell Environ., 15, 271-282, 1992.

Hassan, I. A., Ashmore, M. R., and Bell, J. N. B.: Effects of $\mathrm{O}_{3}$ on the stomatal behavior of Egyptian varieties of radish (Raphanus sativus $1 \mathrm{cv}$ baladey) and turnip (Brassica rapa $1 \mathrm{cv}$ sultani), New Phytol., 128, 243-249, 1994.

Heagle, A. S., Reinert, R. A., and Miller, J. E.: Response of white clover to ozone in different environments, J. Environ. Qual., 25, 273-278, 1996

Jones, H.: Stomatal control of photosynthesis and transpiration, J. Exp. Bot., 49, 387-398, 1998.

Karlsson, P., Uddling, J., Braun, S., Broadmeadow, M., Elvira, S., Gimeno, B., Le Thiec, D., Oksaneng, E., Vandermeirenh, K., Wilkinsond, M., and Emberson, L.: New critical levels for ozone effects on young trees based on AOT40 and simulated cumulative leaf uptake of ozone, Atmos. Environ., 38, 2283-2294, 2004.

Lawrence, D. M., Flanner, M. G., Thornton, P. E., Swenson, S. C., Lawrence, P. J., Zeng, Z., Yang, Z.-L., Levis, S., Sakaguchi, K., Bonan, G. B., and Slater, A. G.: Parameterization improvements and functional and structural advances in version 4 of the Community Land Model, J. Adv. Model. Earth Syst., 3, M03001, doi:10.1029/2011MS000045, 2011.

Lombardozzi, D. L., Sparks, J. P., Bonan, G. B., and Levis, S.: Ozone exposure causes a decoupling of conductance and photosynthesis: Implications for the Ball-Berry stomatal conductance model, Oecologia, 169, 651-659, 2012.

Maier-Maercker, U.: Experiments on the water balance of individual attached twigs of Picea abies (L) Karst in pure and ozoneenriched air, Tree. Struct. Funct., 11, 229-239, 1997.

Maier-Maercker, U. and Koch, W.: Experiments on the control capacity of stomata of Picea abies (1) karst after fumigation with ozone and in environmentally damaged material, Plant Cell Environ., 14, 175-184, 1991.

Manes, F., Vitale, M., Donato, E., and Paoletti, E.: $\mathrm{O}_{3}$ and $\mathrm{O}_{3}+\mathrm{CO}_{2}$ effects on a mediterranean evergreen broadleaf tree, holm oak (Quercus ilex 1.), Chemosphere, 36, 801-806, 1998.

Manes, F., Donato, E., and Vitale, M.: Physiological response of $\mathrm{Pi}$ nus halepensis needles under ozone and water stress conditions, Physiol. Planta., 113, 249-257, 2001.

Martin, M., Farage, P., Humphries, S., and Long, S.: Can the stomatal changes caused by acute ozone exposure be predicted by changes occurring in the mesophyll? A simplification for models of vegetation response to the global increase in tropospheric elevated ozone episodes, Aust. J. Plant Physiol., 27, 211-219, 2000.

Matyssek, R., Gunthardt-Goerg, M., Keller, T., and Scheidegger, C.: Impairment of gas-exchange and structure in birch leaves $(B e$ tula pendula) caused by low ozone concentrations, Tree. Struct. Funct., 5, 5-13, 1991.
Maurer, S., Matyssek, R., GunthardtGoerg, M. S., Landolt, W., and Einig, W.: Nutrition and the ozone sensitivity of birch (Betula pendula): 1. Responses at the leaf level. Tree. Struct. Funct., 12, 1-10, 1997.

McLaughlin, S. B., Wullschleger, S. D., Sun, G., and Nosal, M.: Interactive effects of ozone and climate on water use, soil moisture content and streamflow in a southern appalachian forest in the USA, New Phytol., 174, 125-136, 2007.

Mikkelsen, T. N.: Physiological-responses of fagus-sylvatica 1 exposed to low-levels of ozone in open-top chambers, Tree. Struct. Funct. 9, 355-361, 1995.

Mills, G., Hayes, F., and Wilkinson, S.: Chronic exposure to increasing background ozone impairs stomatal functioning in grassland species, Global Change Biol., 15, 1522-1533, 2009.

Misson, L., Panek, J., and Goldstein, A.: A comparison of three approaches to modeling leaf gas exchange in annually droughtstressed ponderosa pine forests, Tree Physiol., 24, 529-541, 2004.

Morgan, P., Ainsworth, E., and Long, S.: How does elevated ozone impact soybean? A meta-analysis of photosynthesis, growth and yield, Plant Cell Environ., 26, 1317-1328, 2003.

Noormets, A., Sober, A., Pell, E. J., Dickson, R. E., Podila, G. K., Sober, J., Isebrands, J. G., and Karnosky, D. F.: Stomatal and non-stomatal limitation to photosynthesis in two trembling aspen (Populus tremuloides michx.) clones exposed to elevated $\mathrm{CO}_{2}$ and/or $\mathrm{O}_{3}$, Plant Cell Environ., 24, 327-336, 2001.

Novak, K., Schaub, M., Fuhrer, J., Skelly, J. M., Hug, C., Landolt, W., Bleuler, P., and Krauchi, N.: Seasonal trends in reduced leaf gas exchange and ozone-induced foliar injury in three ozone sensitive woody plant species, Environ. Poll., 136, 33-45, 2005.

Nunn, A. J., Wieser, G., Reiter, I. M., Haberle, K. H., Grote, R., Havranek, W. M., and Matyssek, R.: Testing the unifying theory of ozone sensitivity with mature trees of Fagus sylvatica and Picea abies, Tree Physiol., 26, 1391-1403, 2006.

Ojanpera, K., Patsikka, E., and Ylaranta, T.: Effects of low ozone exposure of spring wheat on net $\mathrm{CO}_{2}$ uptake, rubisco, leaf senescence and grain filling, New Phytol., 138, 451-460, 1998.

Oleson, K., Lawrence, D. M., Bonan, G. B., Flanner, M., Kluzek, E., Lawrence, P., Levis, S., Swenson, S., Thornton, P., Dai, A., Decker, M., Dickinson, R., Feddema, J., Heald, C., Hoffman, F., Lamarque, J., Mahowald, N., Niu, G., Qian, T., Randerson, J., Running, S., Sakaguchi, K., Slater, A., Stockli, R., Wang, A., Yang, Z., Zeng, X., and Zeng, X.: Technical description of version 4.0 of the community land model (CLM), NCAR Technical Note NCAR/TN-478+STR, http://www.cesm. ucar.edu/publications/ (last access: August 2012), 2010.

Ollinger, S., Aber, J., and Reich, P.: Simulating ozone effects on forest productivity: Interactions among leaf-, canopy-, and standlevel processes, Ecol. Appl., 7, 1237-1251, 1997.

Ollinger, S., Aber, J., Reich, P., and Freuder, R.: Interactive effects of nitrogen deposition, tropospheric ozone, elevated $\mathrm{CO}_{2}$ and land use history on the carbon dynamics of northern hardwood forests, Global Change Biol., 8, 545-562, 2002.

Paoletti, E.: Ozone slows stomatal response to light and leaf wounding in a mediterranean evergreen broadleaf, Arbutus unedo, Environ. Poll., 134, 439-445, 2005.

Paoletti, E. and Grulke, N. E.: Does living in elevated $\mathrm{CO}_{2}$ ameliorate tree response to ozone? A review on stomatal responses, Environ. Poll., 137, 483-493, 2005. 
Pearson, M. and Mansfield, T. A.: Interacting effects of ozone and water-stress on the stomatal-resistance of beech (Fagus sylvatica 1), New Phytol., 123, 351-358, 1993.

Pellegrini, E., Francini, A., Lorenzini, G., and Nali, C.: PSii photochemistry and carboxylation efficiency in Liriodendron tulipifera under ozone exposure, Environ. Exp. Bot., 70, 217-226, 2010.

Pinheiro, J., Bates, D., DebRoy, S., Deepayan, S., and the R Development Core Team: nlme: Linear and nonlinear mixed effects models, R package version 3.1-104, http://cran.r-project. org/web/packages/nlme/citation.html, last access: August 2012.

Pleijel, H., Danielsson, H., Ojanpera, K., De Temmerman, L., Hogy, P., Badiani, M., and Karlsson, P.: Relationships between ozone exposure and yield loss in European wheat and potato - a comparison of concentration- and flux-based exposure indices, Atmos. Environ., 38, 2259-2269, 2004.

Qian, T., Dai, A., and Trenberth, K.: Simulation of global land surface conditions from 1948 to 2004, Part i: Forcing data and evaluations, J. Hydrometeorol., 7, 953-975, 2006.

Reich, P. B.: Quantifying plant response to ozone: A unifying theory, Tree Physiol., 3, 63-91, 1987.

Reichenauer, T., Bolhar Nordenkampf, H. R., Ehrlich, U., Soja, G., Postl, W. F., and Halbwachs, F.: The influence of ambient and elevated ozone concentrations on photosynthesis in Populus nigra, Plant Cell Environ., 20, 1061-1069, 1997.

Ren, W., Tian, H., Tao, B., Chappelka, A., Sun, G., Lu, C., Liu, M., Chen, G., and Xu, X.: Impacts of tropospheric ozone and climate change on net primary productivity and net carbon exchange of China's forest ecosystems, Global Ecol. Biogeogr., 20, 391-406, 2011.

Schroeder, J., Allen, G., Hugouvieux, V., Kwak, J., Waner, D.: Guard cell signal transduction, Ann. Rev. Plant Physiol., 52, 627-658, 2001.
Sharma, P., Sober, A., Sober, J., Podila, G. K., Kubiske, M. E., Mattson, W. J., Isebrands, J. G., and Karnosky, D. F.: Moderation of $\mathrm{CO}_{2}$-induced gas exchange responses by elevated tropospheric $\mathrm{O}_{3}$ in trembling aspen and sugar maple, Ekologia (Bratislava), 22, 318-331, 2003.

Sitch, S., Cox, P. M., Collins, W. J., and Huntingford, C.: Indirect radiative forcing of climate change through ozone effects on the land-carbon sink, Nature, 448, 791-794, 2007.

Soldatini, G. F., Lorenzini, G., Filippi, F., Nali, C., and Guidi, L.: Photosynthesis of two poplar clones under long-term exposure to ozone, Physiol. Plant., 104, 707-712, 1998.

Tjoelker, M. G., Volin, J. C., Oleksyn, J., and Reich, P. B.: Interaction of ozone pollution and light effects on photosynthesis in a forest canopy experiment, Plant Cell Environ., 18, 895-905, 1995.

Torsethaugen, G., Pell, E., and Assmann, S.: Ozone inhibits guard cell $\mathrm{K}^{+}$channels implicated in stomatal opening, P. Natl. Acad. Sci. USA, 96, 13577-13582, 1999.

von Caemmerer, S. and Farquhar, G. D.: Some relationships between the biochemistry of photosynthesis and the gas-exchange of leaves, Planta, 153, 376-387, 1981.

Wittig, V. E., Ainsworth, E. A., and Long, S. P.: To what extent do current and projected increases in surface ozone affect photosynthesis and stomatal conductance of trees? A meta-analytic review of the last 3 decades of experiments, Plant Cell Environ., 30, 1150-1162, 2007.

Zheng, Y., Shimizu, H., and Barnes, J. D.: Limitations to $\mathrm{CO}_{2}$ assimilation in ozone-exposed leaves of plantago major, New Phytol., 155, 67-78, 2002. 